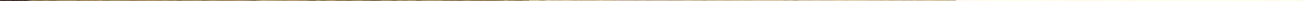



: 7 Th Congress, $\}$ HOUSE OF REPRESENTATIVES. \{ Dooument Qd Session. No. 207.

Bulletin No. 207

Series E, Chemistry and Physics, 36

DEPARTMENT OF THE INTERIOR

UNITED STATES GEOLOGICAL SURVEY

GHARLES D. WALCOTT, DIRECTOR

THE

\title{
ACTION OF AMMONIUM CHLORIDE UPON SILICATES
}

BY

\begin{abstract}
FRANK WIGGIAESWORTH SILARKE
\end{abstract}
AN1)

GEORGE: STHIGER

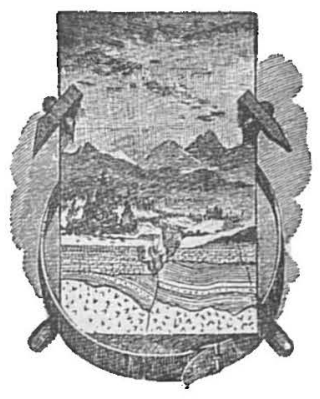

WASHINGTON

GOVERNMENT PRINTIG OFFICE

1902 



\section{CONTENTS.}

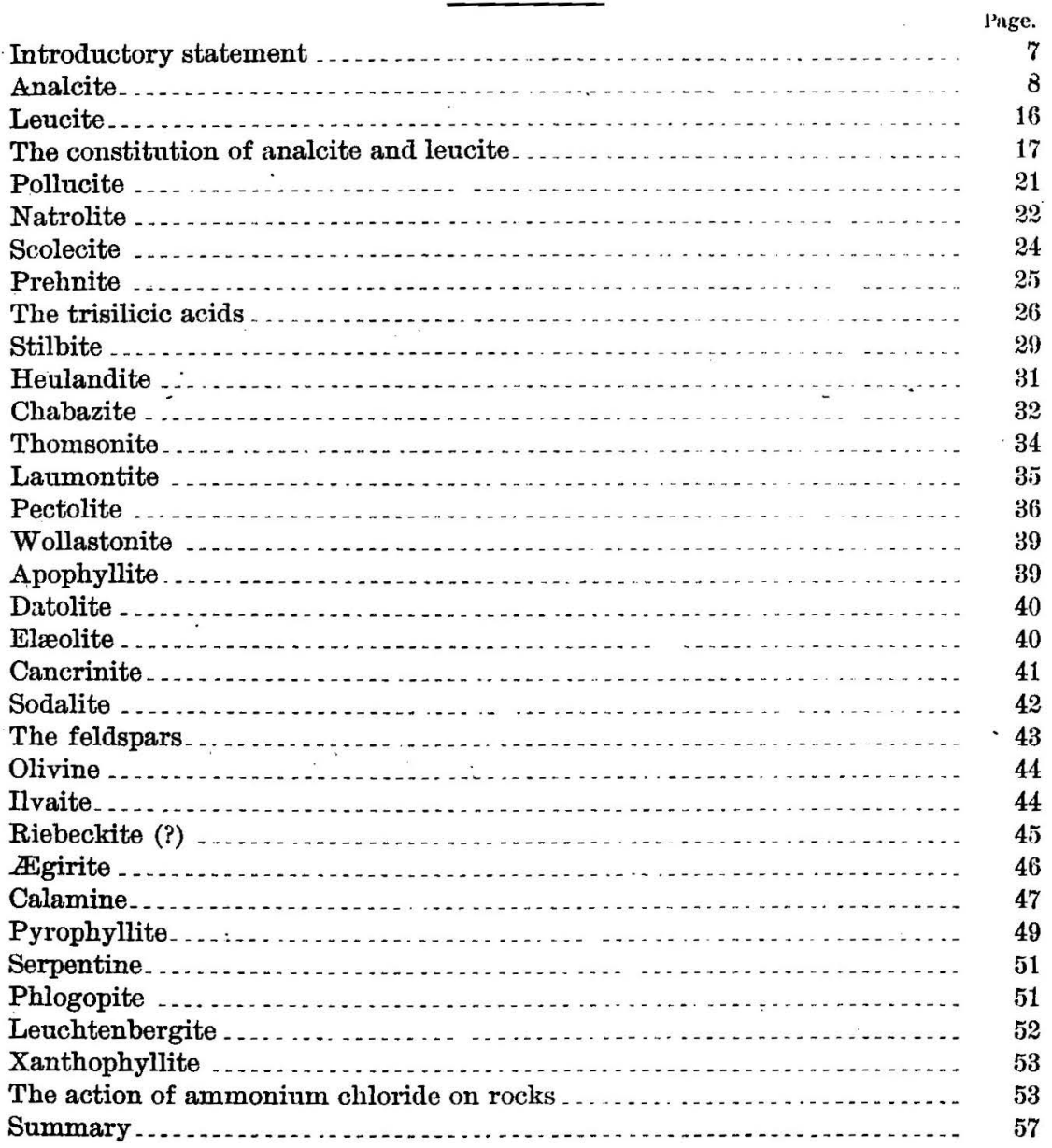





\section{LETTER OF TRANSMITTAL.}

\section{DEPARTMENT OF THE INTERIOR,}

United States Geological Survey, Washington, D. C., September 26, 1902.

SIR: I have the honor to transmit herewith a memoir by Messrs. Clarke and Steiger on the action of ammonium chloride upon silicates, with the recommendation that it be published as a bulletin. These researches are of great geological importance for the light they throw upon the rational constitution of minerals. They are based on a method which is wholly novel and which is capable of wide application. The work is most creditable to the authors and to the United States Geological Survey.

Very respectfully, your obedient servant,

GEORGE F. BECKER, Geologist in Charge, Division of Chemical and Physical Research.

Hon. Charles D. Walcott,

Director United States Geological Survey. 



\section{THE ACTION OF AMMONIUM CHLORIDE UPON SILICATES.}

By Frank Wigglesworth Clarke and George Steiger.

\section{INTRODUCTORY STATEMENT.}

In a series of investigations by Clarke and Schneider, which wer carried out in the laboratory of the United States Geological Survey between the years 1889 and 1892 , "a number of reactions were studied which shed some light upon the constitution of the natural silicates. Among these reactions two were of peculiar interest, on account of their simplicity and the ease with which they conld be applied.

First, in the case of talc, it was found that one-fourth of the silica could be liberated by ignition; and that the fraction thus set free was measurable by solution in aqueous sodium carbonate. This reaction suggests that other acid metasilicates may behave in a similar way, and that we perhaps have a means of discrimination between such salts and other compounds which simulate them. In other words, an acid metasilicate may be experimentally distinguished from a pseudo-metasilicate by the way in which it splits up when ignited. Evidence bearing upon this supposition will be found in the present paper.

The second of the reactions just referred to is that between dry ammonium chloride, at its temperature of dissociation, and various silicates, different minerals being very differently attacked. Some are completely decomposed, others are affected but slightly, and in certain cases substitutions are produced of a most suggestive character. To a certain extent, the two reactions overlap; that is, each one bears somewhat upon the other, and hence both have received consideration in the present series of researches.

In the earlier stages of our work the several silicates which were studied were heated with dry ammonium chloride in open platinum crucibles. The temperature chosen was $350^{\circ}$, at which point the chloride breaks up into gaseous hydrochloric acid and free ammonia, 
and in this way partial changes were effected. Later, the heatings were performed in sealed combustion tubes, and then the reaction proved to be much more far-reaching. In nearly every case the material taken for investigation was ground up into one large, uniform sample, upou which all the experiments were performed, and in that way the results obtained are comparable with one another. The few exceptions to this rule of procedure will be noticed at the proper places. In testing for soluble silica, a standard solution of sodium carbonate, containing 250 grams to the liter, was used, and here again the experimental conditions have been kept uniform. So much premised, we may proceed to the description of our investigations, species by species, in detail.

\section{ANALCITE.}

Analcite, from many points of view, is a species of peculiar interest, and of late years it has received a great deal of attention. Its formula may be written in various ways, especially as regards the interpretation of its one molecule of water; but evidence too often has yielded before preconceived opinion. Additional evidence is now available, partly from the experiments of Friedel, and partly from the data obtained during the present investigation.

The analcite first examined by us was in well-developed crystals from Wassons Bluff in Nova Scotia. A uniform sample was prepared, as usual, and the analysis, given below, is contrasted with the theoretical composition required by the accepted empirical formula $\mathrm{NaAlSi}_{2} \mathrm{O}_{6} \cdot \mathrm{H}_{2} \mathrm{O}$.

\begin{tabular}{|c|c|c|}
\hline & Found. & Calculated. \\
\hline $\mathrm{SiO}_{2} \ldots \ldots$ & 57.06 & 54.55 \\
\hline $\mathrm{Al}_{2} \mathrm{O}_{3}$ & 21.48 & 23.18 \\
\hline $\mathrm{Fe}_{2} \mathrm{O}_{3}$ & .13 & 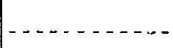 \\
\hline $\mathrm{CaO}$ & .16 & (n............. \\
\hline $\mathrm{Na}_{2} \mathrm{O}$ & 12.20 & 14.09 \\
\hline $\mathrm{H}_{2} \mathrm{O}$ at $100^{\circ}$ & .58 & - - - - \\
\hline \multirow[t]{2}{*}{$\mathrm{H}_{2} \mathrm{O}$ over $100^{\circ}$} & 8.38 & 8.18 \\
\hline & 99.99 & 100.00 \\
\hline
\end{tabular}

Fractions of water.

At $100^{\circ}$
At $180^{\circ} \ldots$
At $260^{\circ} \ldots \ldots$


The fractional water determinations were made by heating in an air bath to constant weight at each temperature up to $300^{\circ}$, and finally over the direct flame. The first fraction, at $100^{\circ}$, is evidently hygroscopic or extraneous water, which can be disregarded. The remainder of the water, 8.38 per cent, belongs to the species. The significance of the analytical figures will be considered later.

Upon boiling the powdered analcite with the standard sodium carbonate solution, 0.73 per cent of silica was extracted. After ignition the mineral in two determinations yielded 1.46 and 1.38 per cent, respectively. The splitting off of silica is, therefore, very slight; and one of the formulæ proposed by Doelter, ${ }^{a} \mathrm{Na}_{2} \mathrm{Al}_{2} \mathrm{Si}_{2} \mathrm{O}_{8}+2 \mathrm{H}_{2} \mathrm{SiO}_{3}$, may be set aside as improbable. Metasilicic acid, or an acid metasilicate, can hardly be present in analcite; although the possibility of a neutral metasilicate, as indicated by the empirical formula, is not excluded. If Doelter's formula were correct, one-half of the silica should be liberated by ignition.

Upon heating analcite with dry ammonium chloride, notable results were obtained even in an open platinum crucible. Sodium chloride was formed, which could be leached out by water and measured, while ammonia, free from chlorine, was retained by the residue to a notable and surprisingly stable degree. The experiments in detail were as follows:

A. Analcite, mixed with four times its weight of ammonium chloride, was heated for four hours'to $350^{\circ}$. There was a gain in weight of 2.18 per cent, and 6.10 per cent of soda, or one-half of the total amount, was converted into $\mathrm{NaCl}$, which was leached out by water, examined as to its purity, and weighed. In the residue 1.20 per cent of silica was extracted by sodium carbonate, showing that no more splitting off had occurred than was previonsly observed. The gain in weight, as will be seen from subsequent experiments, is due to the fact that all of the $\mathrm{NH}_{4} \mathrm{Cl}$ had not been driven off, or else that more water was retained.

B. Analcite was ground up with four times its weight of $\mathrm{NH}_{4} \mathrm{Cl}$, heated for several hours, reground with another fourfold portion of chloride, and heated to $350^{\circ}$ for twenty-one hours. Gain in weight, 0.08 per cent. 5.57 per cent of soda was extracted as chloride.

C. Analcite heated to $350^{\circ}$ for eight hours with four times its weight of $\mathrm{NH}_{4} \mathrm{Cl}$. Loss of weight, 0.10 per cent.

D. Six grams of minera? and 28 of chloride, mixed by thorough grinding, were heated to $350^{\circ}$ for fourteen hours; then were reground with 28 grams of fresh $\mathrm{NH}_{4} \mathrm{Cl}$ and heated for thirty-five hours. Loss of weight, 0.13 per cent. 5.07 per cent of soda was extracted as chloride, plus 0.14 of ammonium chloride unexpelied. 2.03 per cent of silica was rendered solnble in sodium carbonate.

So far three facts are noticeable. First, the weight of the mineral after treatment is almost exactly the same as before, showing that gains and losses have balanced each other. Secondly, little silica has been split off. Thirdly, approximately, but not rigoronsly, one-half of the soda has been converted into $\mathrm{NaCl}$. In $\mathrm{A}$ it was exactly half; in the other experiments, a little less than half. Furthermore, in the sodium chloride dissolved out, there is only a very little ammonium 
chloride, amounting at most to 0.14 per cent, calculated upon the weight of the original mineral.

In the residue of the analcite after extraction of sodium chloride, abundant ammonia can be detected, with either no chlorine or at most a doubtful trace. If, however, the unleached mineral, still retaining its sodium chloride, be heated strongly, say, from $400^{\circ}$ up to redness, $\mathrm{NH}_{4} \mathrm{Cl}$ is regenerated and given off. Its absence, as such, both from the leach and the residue was repeatedly proved. The ammonia and water retained by the analcite after heating to $350^{\circ}$ with ammonium chloride were several times determined, and the following percentages, still reckoned on the original mineral, were found:

\begin{tabular}{|c|c|c|}
\hline & $\mathrm{NH}_{3}$. & $\mathrm{H}_{2} \mathrm{O}$. \\
\hline In $\mathrm{B} \ldots \ldots \ldots$ & 2.03 & 2.25 \\
\hline In $\mathrm{C}$ & 2.19 & 2.00 \\
\hline $\operatorname{In} \mathrm{D}$ & 2.36 & 1.89 \\
\hline " & 2.35 & 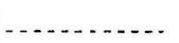 \\
\hline${ }^{-1}$ & 2.06 & $\ldots$ \\
\hline Mean. & 2.20 & 2.04 \\
\hline
\end{tabular}

Correcting the ammonia for the 0.14 of $\mathrm{NH}_{4} \mathrm{Cl}$ found in $\mathrm{D}$, the mean valne becomes 2.15 . The determinations of it were made by three distinct methods, and there is no possible doubt as to its presence.

The composition of the analcite after the treatment with ammonium chloride may now be considered, with the subjoined combination of the data. The $\mathrm{NaCl}$ in $\mathrm{A}, 11.50$ per cent, was in material which had gained 2.18 per cent, and is subject to a correction which reduces the figure to 11.26. In $\mathrm{B}, \mathrm{C}$, and $\mathrm{D}$ the corresponding correction is so small that it may be neglected. The last column gives the composition of the leached residue, recalculated to 100 per cent, after deduction of $\mathrm{NaCl}$ and the soluble silica. The letters refer back to the several experiments, and the little iron is included with the alumina.

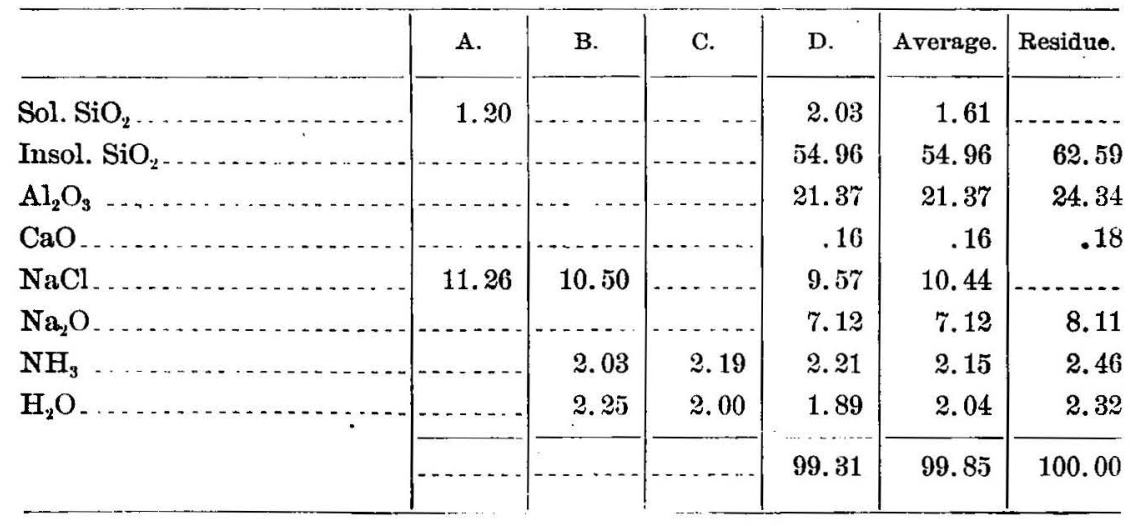


The results thus obtained with analeite from Nova Scotia were se remarkable that further investigation seemed to be neeled upon material of different origin, and with variation in the details of manipulation. The new experiments, which have led to highly interesting consequences, are now to be described.

To the kindness of President Regris Chauvenet, of the State Seliool of Mines, we are indebted for a liberal supply of well-erystallized analcite from North Table Mountain, near Golden, Colo., of which a uniform sample of about $80 \mathrm{grams}$ was prepared. An analysis of the mineral gave the following results:

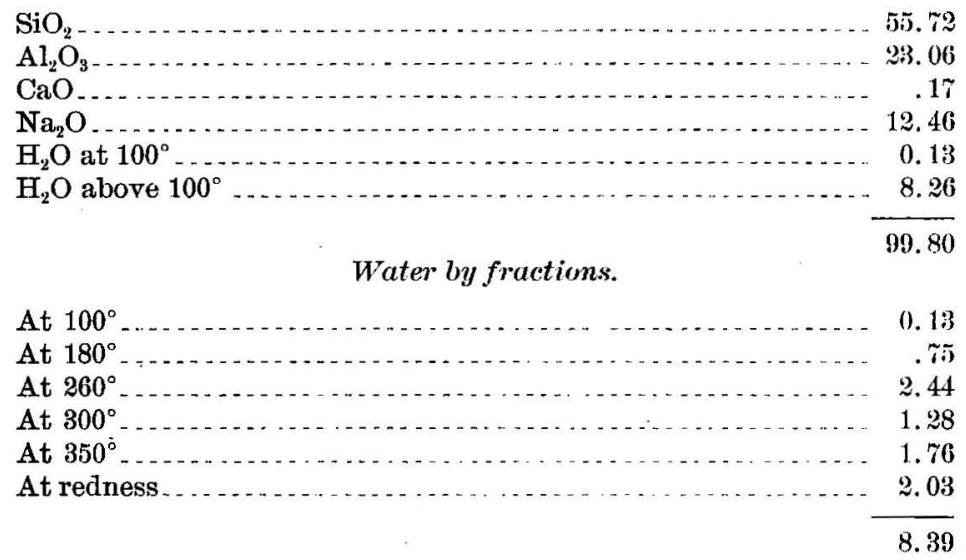

Above a low red heat no further loss of weight was observed. Upon boiling the powdered mineral for fifteen minutes with the standard solution of sodium carbonate, 0.45 per cent of silien was dissolved. After ignition, 0.57 per cent was soluble, which is practically the same amount. No silica was split off by heating. 'The experiments with ammonium chloride fall into two series. The first of these was conducted precisely as in the case of the Nova scotian material, namely, by grinding the powdered mineral into an intimate mixture with four times its weight of the chloride, and heating in an open crucible. In three cases the material, after volatilization of the ammonium chloride, was reground with a fresh amount of the salt, and then heated again. The temperature and duration of the experiments were purposely somewhat raried. After heating, the material was leached out with water, the sodium chloride which had been formed was estimated, and in the residue the fixed ammonia was determined.

In this series there were four experiments, with results as follows:

\begin{tabular}{|c|c|c|c|c|}
\hline & $\begin{array}{c}\text { Hours } \\
\text { heated. }\end{array}$ & $\begin{array}{c}\text { Temper- } \\
\text { ature. }\end{array}$ & $\begin{array}{l}\text { Soda re- } \\
\text { moved. }\end{array}$ & $\begin{array}{l}\text { Ammonin } \\
\text { in residne. }\end{array}$ \\
\hline $\mathbf{A}$ & 28 & 300 & 4.75 & 2.04 \\
\hline B & $8 \frac{1}{2}$ & 350 & 6. 36 & 2.88 \\
\hline C. & 26 & 350 & 3.76 & $1 . \tau^{2}$ \\
\hline D $\ldots \ldots$ & 5 & $340-380$ & 6.70 & 2.85 \\
\hline
\end{tabular}


In the analcite from Nova Scotia the ammonia retained by the leached residue ranged from 2.03 to 2.36 per cent, while the extracted soda varied from 5.07 to 6.10. In two of the new experiments these figures are perceptibly exceeded, and they represent the shortest duration of heating. Prolonged heating seems to be undesirable, and seems to undo a part of the reaction which has taken place; otherwise the results obtained are of the same order as their predecessors. About one-half of the soda in the analcite is converted into chloride, while variable ammonia is retained.

In the second series of experiments a sealed tube was substituted for the open crucible. The powdered analcite was intimately ground with four times its weight of ammonium chloride, as before, and then heated to $350^{\circ}$ in a tube furnace for from four to eleven hours. Under these conditions practically the whole of the soda in the mineral was converted into sodium chloride, while all of the liberated ammonia was absorbed by the residual silicate. Upon leaching the contents of the tube with water, to remove sodium and ammonium chlorides, a residue was obtained which exhibited constant composition whether dried at $100^{\circ}$ or at the ordinary temperature of the air. Three samples of the residue were prepared and analyzed; other samples were partially examined and used for subsidiary experiments. The three analyses, lettered for future reference, were as follows, the analcite itself being included in the table for comparison:

\begin{tabular}{|c|c|c|c|c|}
\hline . & Analcite. & Residue A. & Residue B. & Residue C. \\
\hline $\mathrm{SiO}_{2} \ldots \ldots \ldots$ & 55.72 & 61.93 & 61.68 & 61.79 \\
\hline $\mathrm{Al}_{2} \mathrm{O}_{3} \ldots \ldots \ldots \ldots$ & 23.06 & 25.21 & 25.33 & 25.24 \\
\hline $\mathrm{CaO} \ldots \ldots \ldots$ & .17 & ( & & $\ldots$ \\
\hline $\mathrm{Na}_{2} \mathrm{O} \quad \ldots \quad \ldots \ldots$. & 12.46 & .40 & .22 & .28 \\
\hline $\mathrm{NH}_{3} \ldots \ldots \ldots \ldots \ldots$ & $\ldots . .$. & 7.23 & 6.95 & 7.71 \\
\hline $\mathrm{H}_{2} \mathrm{O} \ldots \ldots \ldots \ldots$ & 8.39 & 4.50 & 4.91 & 5.01 \\
\hline . & 99.80 & 99.27 & 99.09 & 100.03 \\
\hline
\end{tabular}

Residue $\mathrm{C}$ was prepared with the greatest care, and was air dried. Exposed over sulphuric acid in a vacuum desiccator for fourteen days, it lost in weight only 0.08 per cent. Tested for chlorine, only a slight trace could be recognized, but upon boiling for fifteen minutes with sodium carbonate solution it yielded 1.97 of soluble silica. After ignition only 1.70 of silica was soluble, or somewhat less than before. Upon heating to constant weight at $300^{\circ}$, only 0.46 per cent was lost, but at $350^{\circ}$ it slowly decomposed, giving off ammonia. At $300^{\circ}$ the compound is stable.

The 0.28 per cent of soda remaining in residue $\mathrm{C}$ may be regarded as representing unaltered analcite, doubtless coarser particles which 
escaped complete transformation. It corresponds to 1.98 per cent of analcite, which, together with the 1.97 of soluble silica and the 0.46 of water lost below $300^{\circ}$, may be deducted from the substance in order to obtain the composition of the definite compound. The latter amounts to 94.72 per cent of the total residue, and agrees very nearly in composition with the formula

$$
2 \mathrm{NH}_{3} \cdot \mathrm{H}_{2} \mathrm{O} \cdot \mathrm{Al}_{2} \mathrm{O}_{3} \cdot 4 \mathrm{SiO}_{2} \text {. }
$$

Recalculating the 94.72 of residue to 100 per cent, we get the following comparison between analysis and theory:

\begin{tabular}{|c|c|c|}
\hline$\cdots$ & Found. & Culculated. \\
\hline $\mathrm{SiO}_{2} \ldots \ldots \ldots \ldots$ & 61.07 & 60.92 \\
\hline $\mathrm{Al}_{2} \mathrm{O}_{3} \ldots \ldots$ & 26.15 & 25. 88 \\
\hline $\mathrm{NH}_{3} \ldots \ldots$ & 8.14 & 8.63 \\
\hline \multirow{2}{*}{$\mathrm{H}_{2} \mathrm{O} \ldots \ldots \ldots$} & 4.64 & 4.57 \\
\hline & 100.00 & 100.00 \\
\hline
\end{tabular}

Written in rational form the compound becomes equivalent to an anhydrous ammonium analcite,

$$
\mathrm{NH}_{4} \mathrm{AlSi}_{2} \mathrm{O}_{6} \text {; }
$$

that is, analcite in which sodium has been replaced by ammonium. From this point of view the reaction between analcite and ammonium chloride becomes a simple case of double decomposition, and is perfectly intelligible. To establish this conclusion, however, corroborative experiments were necessary.

In the first place, the observed equivalency between the sodium lost and the ammonia gained might be due to a mere coincidence, and so far be illusory. One atom of sodium, taking chlorine from ammonium chloride, liberates one molecule of ammonia, the anount which the analcite residue has retained. Suppose more ammonia were present; could it be absorbed?

To answer this question another tube was prepared, with the usual mixture of analcite and ammonium chloride. 'This was covered by a loose plug of glass wool, in front of which we placed enough pure lime to liberate about double the normal amount of ammonia. The tube was then sealed, and heated to $350^{\circ}$, as in the previous experiments. Upon opening the tube, a strong outrush of ammonia was noticed; but in the leached and thoroughly washed residue, only 7.52 per cent of ammonia was found. This quantity agrees with that from the previous samples, and shows that the limit of the reaction has been practically reached. One molecule of ammonia is retained, and no more.

Still another experiment was tried upon a portion of the residue marked $\mathrm{C}$. If the compound is really an aminonium salt, it should 
be decomposable by caustic soda in such a way as to reverse the reaction by which it had been obtained. The substance, however, is very insoluble, so that the reaction takes place slowly: To phenol phthalein it is absolutely neutral, and with Nessler's reagent it reacts only after long standing.

To settle the question a weighed portion of the compound was boiled in a distilling flask with a 10 per cent solution of sodium hydroxide, to which water was added from time to time. The distillate was collected in a tube containing aqueous hydrochloric acid; and the ammonia which passed over was weighed, ultimately as chloroplatinate. By four hours' boiling 6.90 per cent of ammonium was driven off and determined; and the residue remaining in the flask, after washing until no alkaline reaction could be detected in the washwater, was examined for soda; of which 10.41 per cent was found. The anticipated reaction had taken place, although not completely; it was enough, however, to confirm our opinion, and to establish the nature of the new compound beyond reasonable doubt. Other confirmation was obtained later, from the study of leucite.

The foregoing paragraphs now enable us to understand a phenomenon which we observed in our work with the open erucible. In that case a partial reaction takes place between the analcite and the ammonium chloride, producing, as in the sealed tube, a mixture of an ammonium alumino-silicate with sodium chloride: the two substances being separable by leaching. But if, instead of leaching; the mixture be heated to full redness, ammonium chloride is re-formed and given off, leaving a residue which contains little or no sodium chloride, and is wholly insoluble, or almost so, in water. That is, the reaction which occurs at $350^{\circ}$ is reversed at the higher temerature, and anhydrous analcite, or an isomer of it, is regenerated. Ammonium and sodium again change places, and the original state of molecular equilibrium is restored.

What, now, is the nature of the product obtained in the open crucible after sodium chloride has been removed? Is it a definite intermediate compound or an indeterminate mixture? At first we were inclined to accept the first of these alternatives, and we assigned to the substance the formula $\mathrm{H}_{2} \mathrm{Na}_{2} \mathrm{Al}_{4} \mathrm{Si}_{8} \mathrm{O}_{24} \cdot \mathrm{NH}_{3}$, in which the ammonia plays a part equivalent to that of water. In this expression we were influenced by the researches of Friedel, ${ }^{a}$ who had shown that ammonia could in part replace the "zeolitic" water of analcite; but it now appears that the phenomenon observed by him is quite distinct from that discovered by us, and is, indeed, of an entirely different order. We may, therefore, in accordance with our new data, rearrange the formula, transforming it to that of an ammonium salt, $\mathrm{HNa}_{2} \mathrm{NH}_{4} \mathrm{Al}_{4}$ $\mathrm{Si}_{8} \mathrm{O}_{24}$, the agreement with the analytical figures being approximate only. The results obtained are not sharp enough for certainty.

This product we are now inclined to regard as a mixture. although 
it is not strictly intermediate between analcite and its final ammonium derivative. Only half of the eliminated sodium has been replaced by ammonium, while hydrogen, or water, makes up the deficiency. It seems probable that the reaction in the sealed tube and that in the open crucible are at first essentially the same, but that in the latter case secondary reactions follow, which cause the variations in the final results. In the sealed tube the element of pressure comes into play, and the reaction is complete. In the open crucible pressure is lacking; some ammonia escapes fixation and reacts upon a part of the sodium chloride which was at first formed; hence the composition of the leached residue is essentially modified. This residue may be a definite compound, but the case in its favor is unproved and the presumption is rather against it.

The most remarkable fact developed by the foregoing experiments is the easy replaceability of the soda in analcite. This replaceability, however, is not limited to the substitution of ammonium for sodium; it appears to extend to other bases as well, and this we have proved in the case of silver. This is illustrated by three experiments upon the Colorado analcite, as follows:

A. Analcite, intimately mixed with dry silver nitrate, was heated in a sealed tube to $400^{\circ}$ for four hours.

B. Analcite and silver nitrate were heated in a sealed tube to $250^{\circ}$ for four hours.

C. Ammonium analcite, mixed with dry silver nitrate, was heated in a sealed tube to $250^{\circ}$ for four hours.

All the products of these heatings were leached with water, and washed until the filtrates gave no test for silver; the residues were then dried on the water bath. The product in each case was a white powder not differing in appearance from the original material.

The analyses of the different portions are given below, together with the composition of the theoretical compound, $\mathrm{AgAlSi} \mathrm{O}_{2} \cdot \mathrm{H}_{2} \mathrm{O}$, which is given in column $\mathrm{D}$.

\begin{tabular}{|c|c|c|c|c|}
\hline$e^{\circ}$ & A. & B. & c. & D. \\
\hline $\mathrm{SiO}_{2}$ & 41.31 & 40.08 & 42.69 & 39.35 \\
\hline $\mathrm{Al}_{2} \mathrm{O}_{3}$ & 16.44 & 16. 29 & 18.22 & 16.72 \\
\hline $\mathbf{A g}_{2} \mathrm{O}$ & 37.45 & 36.91 & 32.01 & 38.03 \\
\hline $\mathrm{Na}_{2} \mathrm{O} \ldots \ldots$ & .85 & .81 & .68 & -...... \\
\hline $\mathrm{H}_{2} \mathrm{O} \ldots \ldots$ & 4. 29 & 5.86 & 6.08 & 5.90 \\
\hline $\mathrm{NH}_{3} \ldots \ldots$ & & & .69 & \\
\hline Nitrates...... & none & none & none & $\ldots$ \\
\hline$\cdot$ & 100.34 & 99.95 & 100.37 & 100.00 \\
\hline
\end{tabular}

From preparation A, 13.13 per cent of the soda in the original mineral was found in the leach water; and in B, 12.57 per cent. These quantities are slightly in excess of the amount actually present in the analcite, for the reason that a little other material which passed into 
the filtrates was not separated from the soda. It is enough to show that a true silver analcite has been formed, and that the transformation is practically complete. A similar reaction takes place between silver nitrate and chabazite, but the product as yet has not been exhaustively examined. The reaction, it will be observed, is analogous to that by which silver ultramarine is produced, and it suggests a promising line of experimentation for the future.

\section{LEUCITE.}

Between analcite and leucite the closest analogies have long been recognized. The two minerals bave similar composition, they resemble each other in crystalline form, and they yield, upon alteration, products of the same order. Recently also, analcite, like leucite, has been identified as a not uncommon constituent of volcanic rocks; analcite basalt being a good example. In view of these resemblances it was plainly desirable to compare the minerals by means of the ammonium chloride reaction, a task which has been performed with satisfactory results.

In a preliminary experiment a sample of leucite taken without regard to purity was heated with ammonium chloride to $350^{\circ}$ in a sealed tube. Potassium chloride was formed corresponding to 18.06 per cent of potash, and in the leached residue 6.90 per cent of ammonia was found. The foreseen reaction had occurred, and more careful work was accordingly undertaken.

Our material consisted of a large, irregular crystal of leucite from Vesuvius, which yielded about 20 grams of the pure mineral. This was ground to a uniform sample, and a portion of it was analyzed; the analysis will be given presently. The sealed-tube experiments were conducted precisely as in the case of analcite, and they confirmed both the preliminary test and our anticipations. Chlorides were formed equivalent to 18.53 per cent of potash, 1.08 of soda, and 0.08 of alumina; the reaction, therefore, was very nearly complete. The leached residue was then analyzed, and the data, compared with the analysis of the original mineral, were as follows:

\begin{tabular}{|c|c|c|}
\hline & Leucite. & Residue. \\
\hline $\mathrm{SiO}_{2}-$ & 55.40 & 60.63 \\
\hline (1... & 23.69 & $26.4-4$ \\
\hline $\mathrm{CaO} \ldots \ldots$ & .16 & trace \\
\hline $\mathbf{K}_{2} \mathrm{O} \ldots$ & 19.54 & .50 \\
\hline $\mathrm{Na}_{2} \mathrm{O}$ & 1.25 & .25 \\
\hline $\mathrm{NH}_{\mathbf{3}} \ldots \ldots \ldots$ & $\ldots . .$. & 7.35 \\
\hline \multirow[t]{2}{*}{$\mathrm{H}_{2} \mathrm{O}$} & .24 & 5.1i \\
\hline & 100.28 & $100.3 t$ \\
\hline
\end{tabular}


Leucite, then, gives the same reaction as analcite and yields the same ammonium compound. A closer agreement in the composition of the latter could not reasonably be demanded. Ammonium leucite is formed in both cases by ordinary double decomposition in a state of approximate purity; the first silicate of ammonium, we think, which has ever been prepared.

As a further check upon the results so far obtained, an attempt was made to transform ammonium leucite into the corresponding lime salt, $\mathrm{CaAl}_{2} \mathrm{Si}_{4} \mathrm{O}_{12}$, by fusion with calcium chloride. The ammonium leucite was mixed with a saturated solution of calcium chloride, which was evaporated to dryness, then heated gradually to dehydration, and finally fused. Ammonium chloride was given off and identified. Upon treating the fused mass with water, filtering and thoroughly washing the residue, a white powder was obtained which, after drying at $100^{\circ}$, was analyzed. It was also examined microscopically by $\mathrm{Mr}$. J. S. Diller, who found it to consist of apparently isotropic grains, showing traces of incipient crystallization. The following analysis is contrasted with the theoretical composition of calcium leucite, from which it varies considerably.

\begin{tabular}{|c|c|c|}
\hline & Found. & Calculated. \\
\hline $\mathrm{SiO}_{2} \ldots .$. & 54.35 & 60.30 \\
\hline $\mathrm{Al}_{2} \mathrm{O}_{3} \ldots \ldots$ & 26.23 & 25.63 \\
\hline $\mathrm{CaO}$ & 17.38 & 14.07 \\
\hline $\mathrm{K}_{2} \mathrm{O}_{\ldots}$ & .16 & ....... \\
\hline $\mathrm{Na}_{2} \mathrm{O}$ & .25 & \\
\hline Cl & .28 & $\ldots$ \\
\hline \multirow[t]{2}{*}{ Loss on ignition } & 1.24 & ...... \\
\hline & 99.89 & 100.00 \\
\hline
\end{tabular}

Evidently the desired salt was not definitely obtained, and the product appears to be a mixture. The reaction, however, tends in the right direction, and deserves further study under other conditions. Probably the water which was present in the mixture of silicate and chloride took part in the changes produced, although of this we can not be certain. It is interesting to note that the product obtained approximates in composition to the meteoric mineral maskelynite, which is regarded by Groth as probably equivalent to a calcium leucite.

\section{THE CONSTITUTION OF ANALCITE AND LEUCITE.}

In all of the earlier attempts to discuss the constitution of analcite the molecule of water which it contains has been a chief element of uncertainty. Should it be regarded as representing hydroxyl or as 9506-No. $207-02-2$ 
water of crystallization? That question arose first of all. Under the first interpretation analcite became a diorthosilicate: $\mathrm{AlNaH}_{2} \mathrm{Si}_{2} \mathrm{O}_{7}$; under the latter its equivalency with leucite appeared. The researches of Friedel, however, have settled this question in part, and whatever the function of the water may be it is something outside of the true chemical molecule; for all the water can be expelled from analcite by heat, without destruction of the crystalline nucleus, the anhydrous salt, and it is taken up again upon exposure of the dehydrated mineral to moist air. But whatever its mode of union may ultimately prove to be, the amount of water in analeite corresponds to the simple molecular ratio which is shown in the ordinary formula of the species. One molecule of analcite holds a certain definite number of water molecules, and Friedel's observations are not incompatible with the idea that these are retained with varying degrees of tenacity. This idea is suggested by the various series of fractionation experiments which have been made from time to time by independent workers, even though the data are not by any means concordant. Thus Lepierre ${ }^{a}$ found that half the water of analcite was driven off at or below $300^{\circ}$, the other half above $440^{\circ}$. In our own experiments threefourths were expelled at $300^{\circ}$, the remaining fourth being held up to a much higher but undetermined temperature. In both series the water fractions are represented by fourths, but Friedel's experiments $^{b}$ indicate a continuity of loss in weight of a quite dissimilar order. Friedel holds that all of the water fractionations heretofore made upon analcite are fallacious, and that no definite fractions can be identified-a conclusion strongly supported by his own data, evell though the proof is not absolutely positive. The most that can be said is that the weight of evidence so far is in favor of Friedel's contention, but that additional investigation is necessary in order to reconcile all discrepancies. The full significance of the water in analcite remains unknown.

Eliminating the water from analcite, the empirical formulæ for both analcite and leucite appear: at once to be identical in form and to represent salts of ordinary metasilicic acid. Indeed, both minerals have been commonly regarded as metasilicates; but upon this point the production of the ammonium derivatives now sheds a new light. In the formation of the latter compounds the fixed bases of the original salts have been replaced by a volatile base, and the substances so formed split up upon ignition in such a way as to give evidence regarding their constitution.

For example, if ammonium leucite is a true metasilicate, a salt of the acid $\mathrm{H}_{2} \mathrm{SiO}_{3}$, it should break up, when ignited, in accordance with the following equation:

$$
2 \mathrm{NH}_{4} \mathrm{Al}\left(\mathrm{SiO}_{3}\right)_{2}=\mathrm{Al}_{2}\left(\mathrm{SiO}_{3}\right)_{3}+2 \mathrm{NH}_{3}+\mathrm{H}_{2} \mathrm{O}+\mathrm{SiO}_{2} ;
$$


that is, one-fourth of the silica ought to be set free, measurable by extraction with sodium carbonate solution. No such splitting off occurs, however. An ammonium leucite which already contained 1.97 per cent of soluble silica gave only 1.70 per cent after ignition; hence no additional silica had been liberated. We may conclude, therefore, that analcite and leucite are not true metasilicates, but pseudo-compounds, either salts of a polymer of metasilicic acid or mixtures of ortho- and trisilicates analogous to those which we find among the plagioclase feldspars and in the mica group.

In order to discuss the constitution of analcite, let us recur to our analysis of the variety from Nova Scotia. It is at once evident from the eomparison made on a preceding page that our sample of the mineral varies notably in composition from the requirements of theory. The silica is $2 \frac{1}{2}$ per cent too high, while alumina and soda are correspondingly low. No probable impurity and no presumable errors of manipulation can account for so great a divergence. If we consult other analyses, as we find them tabulated in manuals like those of Dana and Hintze, we shall find other cases resembling this, and also examples of variation in the opposite direction, with silica low and an apparent excess of bases. Most analcite gives quite sharply the metasilicate ratios required by the accepted formula; but the variations from it are large enough, common enough, and regular enough to command attention. The analyses are not all covered by the recognized theory, and the apparent irregularities are not fortuitous, but are systematic in character.

One explanation of the seeming anomalies is simple and clear. If analcite, instead of being a metasilicate, is really a mixture of ortho and trisilicate, then all of the analyses become intelligible. In most cases the two salts are commingled in the normal ratio of $1: 1$, but in our analcite the trisilicate predominates, while in some other samples the ortho-salt is in excess. All reduce alike to the simple expression

$$
\mathrm{NaAlX} \cdot \mathrm{H}_{2} \mathrm{O} \text {, }
$$

in which $\mathrm{X}$ represents $\mathrm{nSiO}_{4}+\mathrm{mSi}_{3} \mathrm{O}_{8}$, a formula which agrees with evidence from various other sources.

For example, analcite may be derived in nature either from albite, AlNaSi ${ }_{3} \mathrm{O}_{8}$, or nephelite, $\mathrm{AlNaSiO}_{4}$, and on the other hand alterations of it into feldspars have been observed. Its closest analogue, leucite, has yielded pseudomorphs of orthoclase and elæolite, while leucite and analcite are mutually convertible each into the other. The evidence of this character-the evidence of relationship between analcite and other species-is varied and abundant, and the simplest conclusion to be drawn from it is that which has been given. Every alteration, every derivation, every variation in the composition of analcite points to the same belief. The consistency of the data can not well be denied. 
In the case of a normal analcite-that is, one which conforms to the usual empirical formula- the expression which best represents thesc relations is

$$
\mathrm{Al}_{4} \mathrm{Na}_{4}\left(\mathrm{SiO}_{4}\right)_{2}\left(\mathrm{Si}_{3} \mathrm{O}_{8}\right)_{2} \cdot 4 \mathrm{H}_{2} \mathrm{O}
$$

and leucite is the corresponding potassium salt, but anhydrous. Structurally this is comparable with the formulæ of garnet, zunyite, sodalite, and noselite, all of which are isometric in crystallization. The more important of the symbols are as follows:

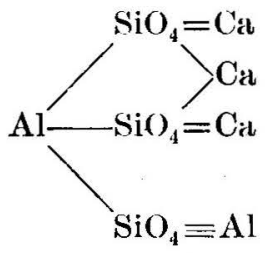

Garnet.

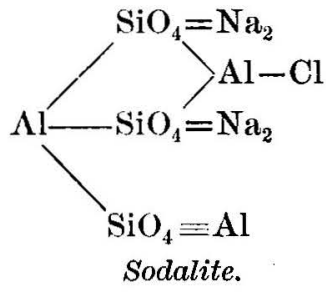

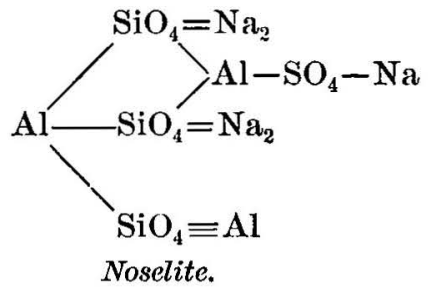
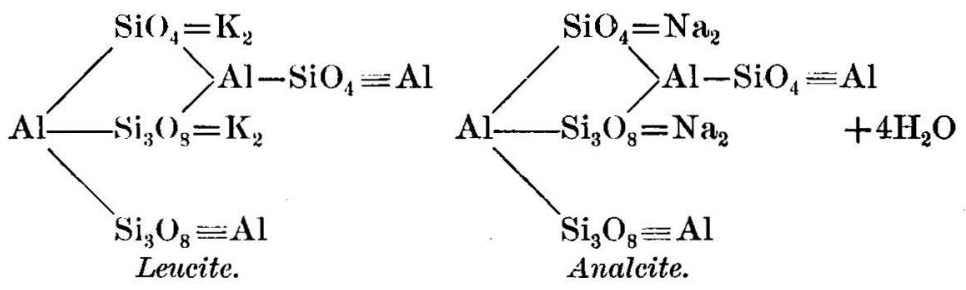

That is, analcite and leucite become members of the garnet-sodalite group of minerals, and their relations to nephelite, albite, etc., natural and artificial, are perfectly clear. In analcite there may be admixtures of strictly analogous ortho- or trisilicate molecules; but these remain to be separately discovered. The ammonium salt corresponding to such a mixture, when ignited, might be expected to give the following reaction:

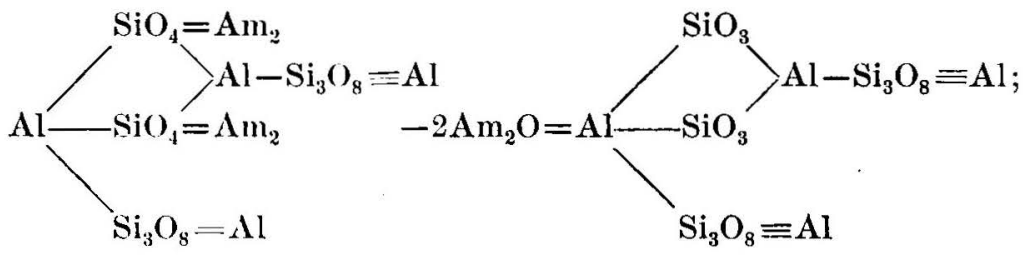

a reaction which is in harmony with our experimental results. In it. no free silica appears; and many, if not all, conditions of the problem are satisfied. One difficulty, however, stands in the way of an unqualified acceptance of these formulæ. Garnet, sodalite, nephelite, albite, etc., are but moderately attacked by ammonium chloride, and so far have yielded no definite ammoxium derivatives. Whether this difference in behavior is constioutional or not it is hardly possible to say, but it must be taken into account in connection with all of the other evidence. We must remember, moreover, that the formulæ 
are not ultimate verities to be blindly accepted. They are simply expressions which represent composition and a wide range of established relationships, and which serve a distinct purpose in the correlation of our knowledge. Properly used, with due recognition of their limitations, they are helpful, and suggest possibilities of research; misused, they may become mischievous. They now satisfy most of the known conditions, and that is a sufficient warrant for their existence.

\section{POLLUCITE.}

On account of the general analogy between pollucite, analcite, and leucite, the first-named species of the three seemed to deserve some attention. Through the kindness of Prof. S. I. Penfield, about 10 grams of very pure material from Hebron, Me., was put at our disposal, and three analyses of it by Wells were alrearly on record. ${ }^{a}$ The average of these analyses is as follows:

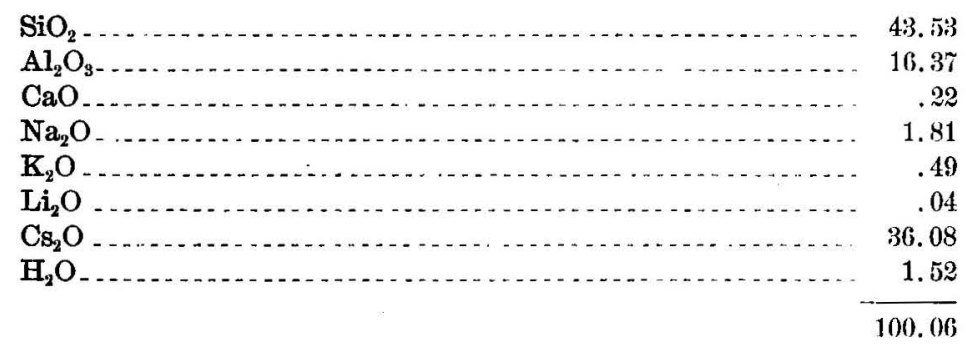

Five grams of the finely powdered mineral was heated in a sealed tube with four times its weight of ammonium chloride to $350^{\circ}$ during forty hours. Upon leaching with water 0.14 per cent of $\mathrm{CaO}, 1.28$ of $\mathrm{Na}_{2} \mathrm{O}$, and 12.30 of $\mathrm{Cs}_{2} \mathrm{O}$ were extracted. Probably the calcium chloride formed contained some potassium chloride, but that point was ignored as irrelevant. 'The air-dried residue had the following composition :

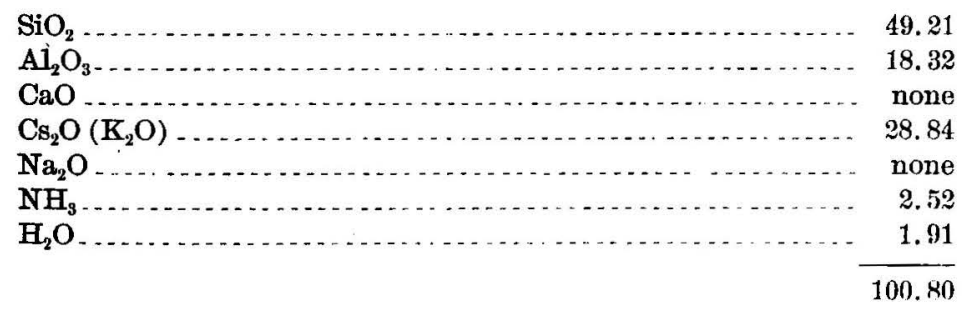

The high summation here is due to reckoning some $\mathrm{KCl}$ as $\mathrm{CsCl}$. Of the silica in this product 2.36 per cent was soluble in the standard solution of sodium carbonate. After ignition, 4.13 per cent was soluble. Some silica, therefore, was split off by heating. 
In a second experiment one gram of pollucite was heated with anmonium chloride for five hours, the other conditions being the same as before. Upon leaching, 11.55 per cent of $\mathrm{Cs}_{2} \mathrm{O}$ was extracted, and a partial analysis of the air-dried residue gave the following data:

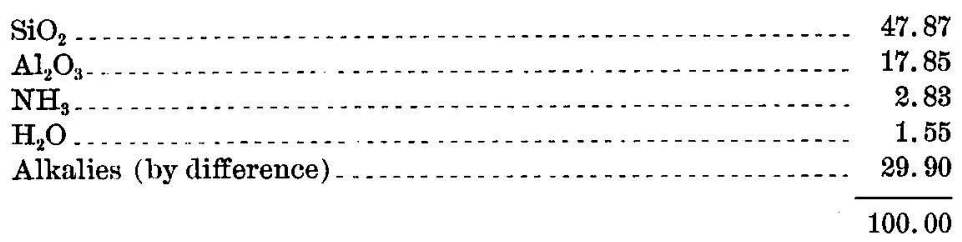

The two products were evidently the same, and only about onethird of the alkalies in the pollucite had been extracted. So, also, the ammonia taken up was only about one-third of that which was retained by analcite and leucite. The transformation, then, is merely partial, and further experimentation seems to be unnecessary, at least for present purposes. The analogy with analcite and leucite is far from perfect.

\section{NATROLITE.}

In a preliminary experiment upon an impure, yellowish natrolite from Aussig in Bohemia, we found that this species was peculiarly well suited to reaction with ammonium chloride. By heating with the reagent in a sealed ube and subsequent leaching with water, 17.56 per cent of bases was extracted, and in the residue 8.29 per cent of ammonia was found. Careful work upon this species was therefore desirable.

The material available for our experiments came from the wellknown locality at Bergen Hill, N. J., and consisted of a mass of slender needles densely matted together. Part of the uniform, ground sample was analyzed, with fractional determinations of the water, and part was used for the sealed tube experiments, precisely as in the research upon analcite and leucite. Three of these experiments were made, and in each case the natrolite was mixed by grinding in an agate mortar with four times its weight of dry ammonium chloride, after which it was heated to $350^{\circ}$ in the sealed tube. Even during the grinding a slight reaction took place, and a distinct smell of ammonia was given off. by the mixture. With pectolite the same smell was perceived. The three experiments may be summarized as follows:

A. Heated eleven hours. Upon leaching, 14.89 per cent of soda and 1.20 of lime were extracted. In the residue 9.26 per cent of ammonia was found.

B. Heated nine hours. Leach not examined. 9.26 of ammonia in residue. The complete analysis of the residue is given farther on.

C. Heated three hours. 14.09 per cent of soda and 0.20 of lime were extracted. The residue contained $8.8 \%$ per cent of ammonia. In this instance the heating 
was relatively brief, in order to learn whether its duration could be advantageously lessened. The reaction was evidently less complete than in experiments $\mathrm{A}$ and $\mathrm{B}$.

In the subjoined table we give first the analysis of the natrolite itself, and then that of the leached residue from experiment $B$. In the latter we found that 0.86 per cent of silica was soluble in sodium carbonate solution, and that soda and lime remained corresponding to $4.61 \mathrm{per}$ cent of the original mineral. Deducting these impurities, together with the 0.42 per cent of hygroscopic water, and recalculating to 100 per cent, we get the reduced composition of the residue. In the last column is given the calculated composition of an anhydrous ammoniumnatrolite, $\left(\mathrm{NH}_{4}\right)_{2} \mathrm{Al}_{2} \mathrm{Si}_{3} \mathrm{O}_{10}$. This compound has evidently been formed to an extent represented by over 94 per cent of the leached natrolite residue. The agreement between theory and even the unreduced analysis is practically conclusive on this point.

\begin{tabular}{|c|c|c|c|c|}
\hline . & $\begin{array}{l}\text { Natrolite } \\
\text { found. }\end{array}$ & $\begin{array}{l}\text { Residue } \\
\text { found. }\end{array}$ & $\begin{array}{l}\text { Residue } \\
\text { rediuced. }\end{array}$ & $\begin{array}{c}\left(\mathrm{NH}_{4}\right)_{2} \mathrm{Al}_{2} \\
\mathrm{Si}_{3} \mathrm{O}_{10} \mathrm{cal}- \\
\text { culatated. }\end{array}$ \\
\hline $\mathrm{SiO}_{2}$ & 46.62 & 53.71 & 53.86 & 54.06 \\
\hline $\mathrm{Al}_{2} \mathrm{O}_{3}$ & 26.04 & 29.94 & 30.52 & 30.43 \\
\hline $\mathrm{CaO} \ldots \ldots$ & 1.48 & .34 & & \\
\hline $\mathrm{K}_{2} \mathrm{O} \ldots$ & none & $\ldots$ & & \\
\hline $\mathrm{Na}_{2} \mathrm{O} \ldots \ldots$ & $15.6 \%$ & $.3 \pi$ & & . . . . \\
\hline $\mathrm{NH}_{3} \ldots \ldots$ & 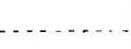 & 9.26 & 9.85 & 10.14 \\
\hline $\mathrm{H}_{2} \mathrm{O}$ at $100^{\circ} \ldots$ & .39 & .42 & & \\
\hline \multirow[t]{2}{*}{$\mathrm{H}_{2} \mathrm{O}$ above $100^{\prime \prime}$} & 10.18 & i. 94 & 5. $\pi$ & ธ. 37 \\
\hline & 100.38 & 99.98 & 100.00 & 100.00 \\
\hline
\end{tabular}

'The fractional water determinations will be griven later, in connection with similar data for scolecite (p. 25).

It may not be superfluous to note that the water given in the last two columns of the foregoing table represents the difference between ammonia and the hypothetical ammonium oxide which has replaced soda.

Two other experiments upon natrolite remain to be noticed. First, the fresh mineral was boiled for fifteen minutes with a 25 per cent sodium carbonate solution: 0.72 per cent of silica dissolved. Similar treatment of ignited natrolite took out 0.62 per cent. No silica is split off by ignition. Ammonium natrolite before ignition yielded 0.85 per cent of soluble silica, and after ignition 0.86 per cent. Here again no silica had been split off from the molecule, and practically none was liberated by the action of the ammonium chloride upon the natrolite. A simple, direct substitution of ammonium for sodium had occurred. 
Heated with ammonium chloride in an open crucible, natrolite gives only a partial reaction. 'This is shown by the earlier' experiments of Schneider and Clarke upon natrolite from Magnet Cove, Arkansas, from which, by a triple heating with the reagent, only 9.50 per cent of soda was extracted out of a total of 15.40 .

\section{SCOLECITE.}

On account of the well-recognized analogy between natrolite and scolecite, the latter mineral seemed to be peculiarly worthy of examination. The specimen at our disposal was a mass of stout, radiating needles, which was collected by one of us at Whale Cove, on the island of Grand Manan, New Brunswick. Scolecite, we believe, has not hitherto been recorded from this locality, and on this account alone the material deserved attention.

Three sealed tube experiments were carried out, essentially as in the case of natrolite, as follows:

A. Heated ten hours at $350^{\circ}$. 13.54 per cent of lime and 0.35 of soda were taken out. The residue contained 8.78 per cent of ammonia.

B. Heated ten hours at $370^{\circ}$. 12.97 of lime and 0.22 of soda were extracted. 8.48 per cent of ammonia in the residne. On account of the excessive temperature of this experiment, some reversion of the converted material had taken place.

C. Heated five hours at $340^{\circ}-350^{\circ}$. Leach not studied. 8.91 per cent of ammonia in residue.

Analyses of the scolecite and of residues $\mathrm{B}$ and $\mathrm{C}$ are given below. The less perfect transformation in the case of $B$ is evident.

\begin{tabular}{|c|c|c|c|}
\hline & Scolecite. & Residue B. & Residue C. \\
\hline $\mathrm{SiO}_{2} \ldots \ldots \ldots$ & 45.86 & 53.39 & 53.69 \\
\hline $\mathrm{Al}_{2} \mathrm{O}_{3} \ldots \ldots \ldots \ldots$ & 25.78 & 30.51 & 30.50 \\
\hline $\mathrm{CaO} \ldots \ldots \ldots$ & 13.92 & .62 & .42 \\
\hline $\mathrm{Na}_{2} \mathrm{O}$ & .41 & undet. & .29 \\
\hline $\mathrm{NH}_{3} \ldots \ldots \ldots$ & $\ldots \ldots . . .$. & 8.48 & 8.91 \\
\hline $\mathrm{H}_{2} \mathrm{O}$ at $100^{\circ} \ldots$ & .40 & .74 & .12 \\
\hline \multirow[t]{2}{*}{$\mathrm{H}_{2} \mathrm{O}$ above $100^{\circ} \ldots \ldots \ldots$} & 13.65 & 6.28 & 6.52 \\
\hline & 100.02 & 100.02 & 100.45 \\
\hline
\end{tabular}

The product of the reaction is plainly the same as that obtained from natrolite, and the identity in type of the two species is perfectly clear. This fact is further emphasized by an experiment upon the solubility of silica. 'lhe fresh scolecite gave up 0.36 per cent of silica to sodium carbonate solution, and the ignited mineral yielded only 0.50 per cent. Again, natrolite and scolecite behave in the same way.

Upon both minerals fractional determinations of the water were made, and the amount lost at each temperature was noted. The 
results, expressed in percentages of the original minerals, were as follows:

\begin{tabular}{|c|c|c|}
\hline \multirow{2}{*}{ Temperature. } & \multicolumn{2}{|c|}{ Water lost. } \\
\hline & Natrolite. & Scolerite. \\
\hline $100^{\circ} \ldots$ & 0.39 & 0.40 \\
\hline $180^{\circ} \ldots$ & .40 & .52 \\
\hline $250^{\circ} \ldots \ldots \ldots$ & $.3 r$ & 4.76 \\
\hline $350^{\circ} \ldots \ldots \ldots \ldots$ & 8.51 & .55 \\
\hline Incipient redness . . . & .72 & 7.72 \\
\hline Full redness ...... & .12 & .04 \\
\hline \multirow[t]{2}{*}{ Over blast ..... } & .06 & .06 \\
\hline & $10.5 r$ & 14.05 \\
\hline
\end{tabular}

Scolecite contains one more molecule of water than natrolite, and that amount, one-third of its total, seems to go off at a lower temperature than the other two molecules. Otherwise the two series of experiments are probably not far apart, and they indicate that the water is in neither case constitutional. The same conclusion is suggested by the existence of the anhydrous ammonium compound, the three formulæ being as follows:

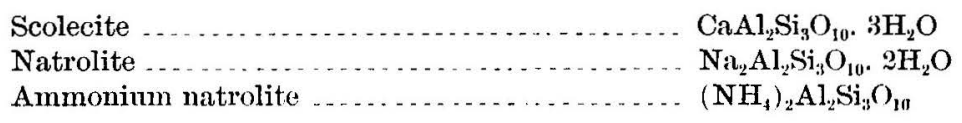

The parallelism is complete; and all three compounds are evidently salts of an acid, $\mathrm{H}_{8} \mathrm{Si}_{3} \mathrm{O}_{11}$, which is probably orthotrisilicie acid, $\mathrm{Si}_{3} \mathrm{O}_{2}(\mathrm{OH})_{8}$. The relations of this acid to its anhydrides will be considered later.

\section{PREHNITE.}

In a former bulletin upon the constitution of the silicates, " one of us attempted to show that natrolite, scolecite, and prehnite were similar in chemical structure, provided that all or part of their water was regarded as constitutional. The formulat then assigned were as follows:

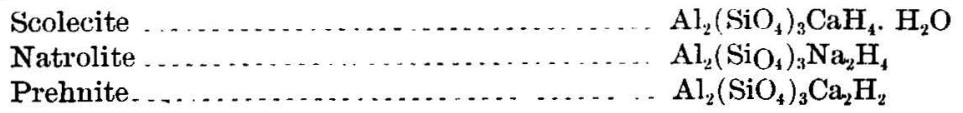

Two of these formulæ must now be abandoned, because of the experimental evidence which we have obtained, but the prehnite remains to be considered. 
The material chosen for examination was an old specimen of prehnite from Paterson, N. J. The analysis of it, with fractional water determinations, is given below:

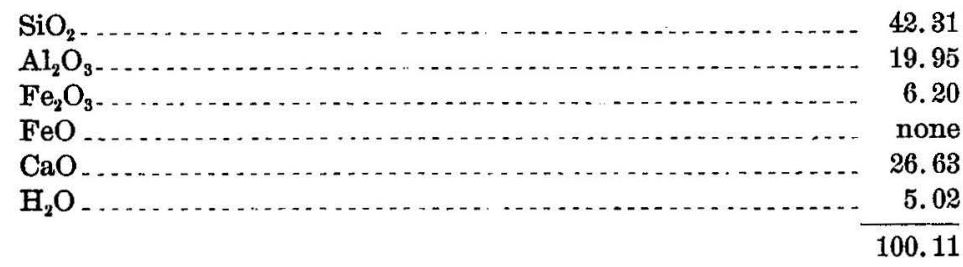

Fractional water.

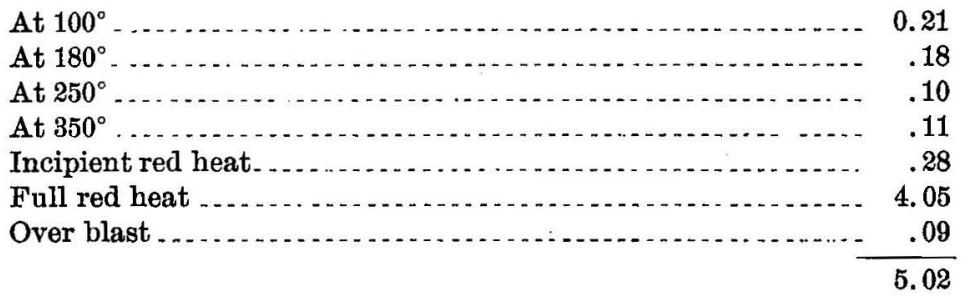

With sodium carbonate sulution, 0.38 per cent of silica was extracted from the fresh mineral. From the ignited prehnite, 1.22 per cent was taken out. Very little silica, therefore, is liberated by ignition.

Two determinations were made of the action of ammonium chloride, as follows:

A. Heated eight hours. On leaching with water, 1.31 per cent of lime and 0.17 of alumina dissolved.

B. Heated twelve hours. 1.41 per cent of lime was extracted, and in the washed residue 0.22 per cent of ammonia was found.

Prehnite, therefore, differs widely from natrolite and scolecite in its behavior with ammonium chloride. Very little action takes place, even upon long heating to $350^{\circ}$ in a sealed tube, and practically no ammonia is absorbed. The water is nore firmly held than was the case with the other two minerals, and is almost certainly to be regarded as constitutional. The orthosilicate formula for prehnite is unaffected by these results, and may stand as fairly probable. Prehnite can not be correlated with natrolite and scolecite on any basis of similar chemical structure.

\section{THE TRISILICIC ACIDS.}

We have already shown that natrolite and scolecite are probably salts of an orthotrisilicic acid, $\mathrm{H}_{8} \mathrm{~S}_{8} \mathrm{O}_{10}$, an acid which is not particularly well known. As it has interesting relations to other compounds, some discussion of its constitution and its derivatives may not be out of place here.

The general theory of the silicic acids is extremely simple. Silicon being a quadrivalent element, its normal acid, the orthosilicic, is 
$\mathrm{Si}(\mathrm{OH})_{4}$. From this, by successively eliminating two molecules of water, two anhydrides may be derived, thus:

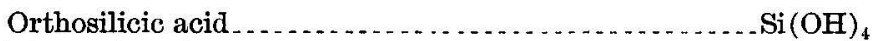

First anhydride, metasilicic acid . . . . . . . . . . . . . . . . $\mathrm{O}=\mathrm{Si}-\ldots(\mathrm{OH})_{2}$

Second anhydride, silicon dioxide $\ldots \ldots \ldots \ldots \ldots \ldots$

These acids, containing one atom of silicon each, may be called the monosilicic acids, and some of their salts are perfectly well known. Olivine and anorthite, for instance, are orthosilicates, while the true metasilicates are represented by talc and pectolite. The evidence in the case of the last-named mineral will be presented later.

When two molecules of orthosilicic acid coalesce, with elimination of water, an orthodisilicic acid is formed, and this is the first member of another series, as follows:

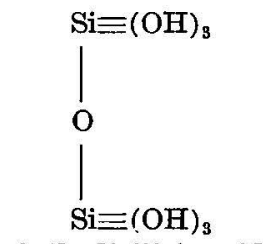

Orthodisilicic acid.

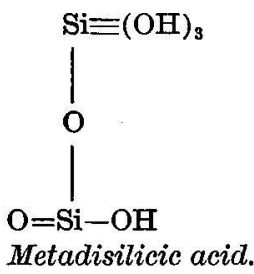

To the first and third of these acids various minerals correspond. The second acid, however, is a polymer of metasilicic acid, but differs from the latter in its possible derivatives. When an acid metasilicate is heated silica is set free, but in the case of a metadisilicate this would not necessarily occur. Possibly leucite and analcite may be metadisilicates, although the evidence so far presented does not support this view. The possibility, however, we are compelled to recognize as one which might ultimately be verified.

With the coalescence of three orthosilicic molecules a series of trisilicic acids begins, and one of these forms salts-the feldspars-which are the most abundant compounds existing in the mineral kingdom. The acids of the series are these:
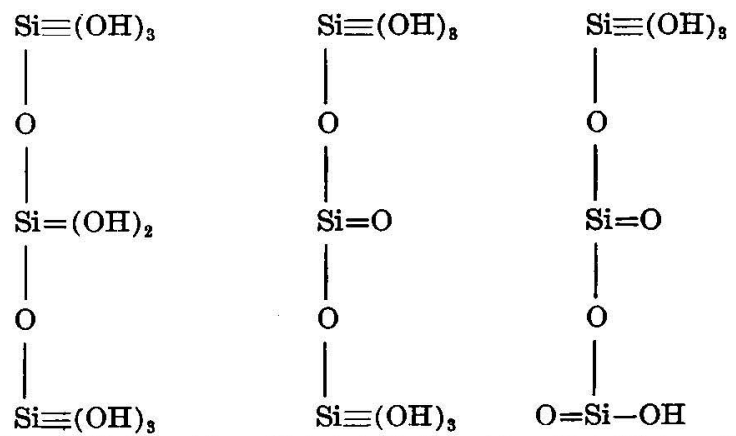

Orthotrisilicic acid. Metatrisilicic acid.

Trisilicic acid.<smiles>O=[Si](O)O[Si](=O)O[Si](=O)O</smiles>

Third anhydride. 
The third anhydride represents an acid to which no known salts correspond. One step further and we have a fourth anhydride, $\mathrm{Si}_{3} \mathrm{O}_{6}$, or empirically $\mathrm{SiO}_{2}$, which may or may not be the true formula of quartz. Quartz is undoubtedly a polymer of $\mathrm{SiO}_{2}$; its most frequent associates are trisilicates-the feldspars-and hence the formula $\mathrm{Si}_{3} \mathrm{O}_{6}$ has a certain degree of plausibility. This suggestion, however, is purely speculative and has no definite scientific value. Its validity would be most difficult to establish.

- From the first of these trisilicic acids natrolite and scolecite appear to be derived. If we ignore the "zeolitic water," which is not a part of the essential silicate molecule, the two compounds may be formulated thus:

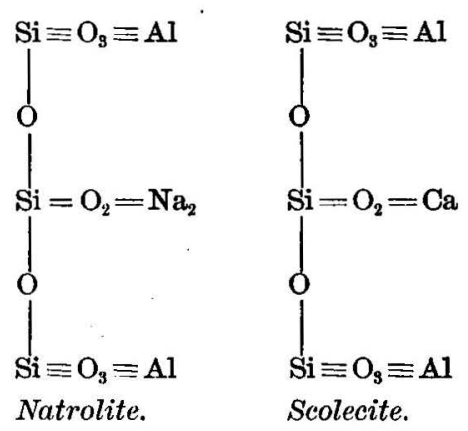

So far, no other salts of this acid have been clearly identified.

The second acid of the series, like the second of the disilicic acids, is a polymer of the ordinary metasilicic compound. It is well understood that many so-called metasilicates are not representatives of the simple acid $\mathrm{H}_{2} \mathrm{Si} \mathrm{O}_{3}$; some of them are mixtures of orthosilicates with salts of the third acid in this group, $\mathrm{H}_{4} \mathrm{Si}_{8} \mathrm{O}_{8}$; other's may be derived from polymers like that which is now under consideration. For example, anhydrous analcite and jadeite are both represented by the empirical formula $\mathrm{NaAlSi}_{2} \mathrm{O}_{6}$, but they differ widely in density, in solubility, and doubtless also in crystalline form. One molecule, then, is much more condensed than the other. If analcite should prove to be a metadisilicate, then jadeite may be its equivalent in the trisilicic series, or it may belong with some still higher polymer. The possibilities are many, but to establish any one of them by proof would demand more evidence than is yet in our possession.

The third member of the trisilicic series is the most important of all, for among its salts are the two feldspars, albite and orthoclase, which together make up fully one-half of the solid crust of the earth. It is also noteworthy from the fact that its formula can be so written 
as to represent two isomeric forms, to which distinct salts probably correspond. The two formulæ are as follows:<smiles>O=[Si](O)O[Si](=O)O[Si](=O)O</smiles><smiles>O=[Si](O)O[Si](O)(O)O[Si](=O)O</smiles>

and their significance is clear when we remember that the ordinary trisilicates are commonly dimorphous. Thus we have orthoclase and soda orthoclase, monoclinic; and albite and microcline triclinic; one pair perhaps belonging to one isomer, the other to the other. The rare minerals eudidymite and epididymite, which are also isomeric trisilicates, further illustrate the same conception; but we can not as yet assign either compound distinetly to either formula.

By an extension of the process herein developed, which is by no means new, higher polysilicic series may be formulated. Since, however, such acids correspond to no definitely known salts, to write their formulæ would be a useless exercise of the imagination. Beyond the trisilicic acids we enter the region of the unknown.

\section{STILBITE.}

The specimen selected for study was a nearly white, typical example from Wassons Bluff, Nova Scotia. The analysis and the fractional water determinations were as follows:

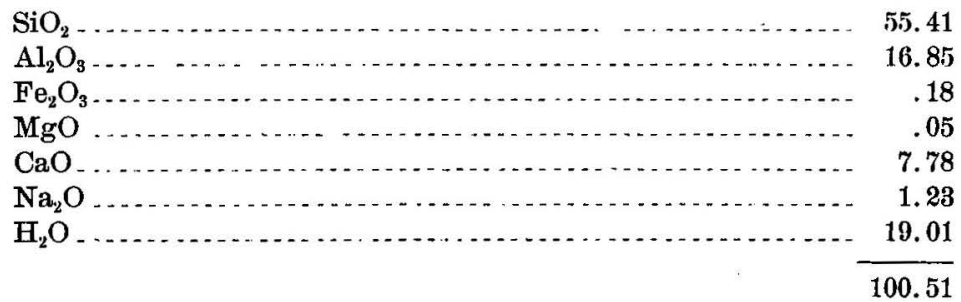

Fractional water.

At $100^{\circ}$

3. 60

At $180^{\circ}$

6.46

At $250^{\circ}$

3. 80

At $350^{\circ}$

2.10

Low redness

2.95

Full redness

.06

Over blast

.04 
On boiling with sodium carbonate, 1.37 per cent of silica went into solution. After ignition, only 1.03 per cent was obtaiued. No silica, therefore, is split off when stilbite is ignited. If the mineral were a hydrous acid metasilicate, $\mathrm{H}_{4} \mathrm{CaAl}_{2} \mathrm{Si}_{6} \mathrm{O}_{18} \cdot 4 \mathrm{H}_{2} \mathrm{O}$, as has been assumed by some authorities, one-third of the silica should have been set free. Hence the metasilicate formula is to be regarded as unsatisfactory. The evidence here presented counts for something against it.

Two samples of the ammonium chloride derivative were prepared. In leaching with water the insoluble residue was washed until the washings gave no reaction for chlorine. The chlorine shown in the subjoined analyses is, therefore, present in an insoluble form and not as adhering ammonium chloride. Dried at $50^{\circ}$ the two products gave the following composition:

\begin{tabular}{|c|c|c|}
\hline & A. & B. \\
\hline $\mathrm{SiO}_{2} \ldots \ldots$ & 60.80 & 60.67 \\
\hline $\mathrm{Al}_{2} \mathrm{O}_{3}$ & 18.36 & 18.25 \\
\hline $\mathrm{CaO}$ & 1.86 & 1.46 \\
\hline $\mathrm{Na}_{42} \mathrm{O}$ & .08 & .15 \\
\hline $\mathrm{NH}_{3} \ldots \ldots$ & . $\quad 5.12$ & 5.13 \\
\hline $\mathrm{H}_{2} \mathrm{O}$ & 12.96 & 13.91 \\
\hline \multirow[t]{2}{*}{$\mathrm{Cl}$} & 1.31 & 1.04 \\
\hline & 100.49 & 100.61 \\
\hline \multirow[t]{2}{*}{ Less $\mathrm{O}_{\ldots} \ldots \ldots \ldots$} & .29 & .23 \\
\hline & 100.20 & 100.38 \\
\hline
\end{tabular}

Sample B was further examined as to the presence of soluble silica, and 1.52 per cent was found. After ignition, only 1.62 per cent went into solution. These results conform to those obtained with the original stilbite, and tend to show that the ammonium derivative is a compound of the same order. In the case of the unignited substance the residue remaining after the removal of soluble silica was thoroughly washed, and then examined for alkali. It was found to contain 9.30 per cent of soda, which shows that the ammonium salt had been transformed back into the corresponding sodium compound.

From the foregoing facts it is clear that stilbite, like the zeolites previously studied, is converted by the action of ammonium chloride into an ammonium salt. That is, sodium and calcium are removed as chlorides, anmonium taking their place to form ammonium stilbite. The reaction, however, is less complete than it was in the cases of analcite and natrolite, but whether this is due to a greater stablity of the stilbite molecule or only to a different degree of fineness in the powder upon which the operations were performed, we can not say. Neither have we any explanation to offer of the retention of chlorine 
by the ammonium derivative. Although the amount, of chlorine is small, it needs to be accounted for.

If we discuss the composition of the stilbite and of its ammonium derivative, the relations between them become very clear. Neglecting the water as "zeolitic," to use Friedel's phrase, and, therefore, as not a part of the chemical molecule, and also rejecting the 1.37 per cent of soluble silica as probably an impurity, the ratios derived from the analysis give this empirical formula for the mineral:

$$
\mathrm{Na}_{40} \mathrm{Ca}_{140} \mathrm{Al}_{332} \mathrm{Si}_{901} \mathrm{O}_{24601} \text {. }
$$

This corresponds to a mixture of ortho- and trisilicates in which $\mathrm{Si}_{3} \mathrm{O}_{8}: \mathrm{SiO}_{4}:: 286: 43$; and uniting these radicles under the indiscriminate symbol $\mathrm{X}$, we have, as a more general expression,

$$
\mathrm{Nat}_{40} \mathrm{Ca}_{141} \mathrm{Al}_{332} \mathrm{X}_{326} \text {; }
$$

or combining monoxide bases,

$$
\mathrm{R}^{\prime \prime}{ }_{160} \mathrm{Al}_{332} \mathrm{X}_{329},
$$

which is essentially $\mathrm{R}^{\prime \prime} \mathrm{Al}_{2} \mathrm{X}_{2}$. Since the $\mathrm{SiO}_{4}$ groups are practically equal in number to the sodium atoms, the stilbite is probably a mixture, very nearly, of $\mathrm{NaAlSiO}_{4}$ and $\mathrm{CaAl}_{2}\left(\mathrm{Si}_{3} \mathrm{O}_{8}\right)_{2}$ in the ratio of $1: 7$ This is in accordance with the well-known theory of Fresenius as to the constitution of the phillipsite group, to which stilbite belongs. Stilbite is mainly a hydrous calcium albite, commingled with varying amounts of corresponding orthosilicates of soda and lime.

For the ammonium derivative similar relations hold. Taking analysis " $B$ " for discussion, rejecting soluble silica and chlorine as impurities, and neglecting all water except that which belongs to the supposable ammonium oxide, the ratios give this formula:

$$
\left(\mathrm{NH}_{4}\right)_{301} \mathrm{Na}_{4} \mathrm{Ca}_{26} \mathrm{Al}_{358} \mathrm{Si}_{985} \mathrm{O}_{2684} \text {. }
$$

Uniting sodium and calcium with ammonium, this becomes

or, more generally,

$$
\mathrm{R}_{357}^{\prime} \mathrm{Al}_{358}\left(\mathrm{Si}_{3} \mathrm{O}_{8}\right)_{314}\left(\mathrm{SiO}_{4}\right)_{43} \text {; }
$$

$$
\mathrm{R}_{35 i}^{\prime} \mathrm{Al}_{358} \mathrm{X}_{35 i},=1: 1: 1 .
$$

The derivative, therefore, is a compound of the same order as the original stilbite, with the ratio of $1: 7$ still holding between the ortho and trisilicate groups. This conclusion, however, ignores the presence of chlorine, and is, therefore, inexact to some extent. We are not dealing with ideally pure compounds.

\section{HEULANDITE.}

Pure, white heulandite from Berufiörd, Iceland, was the material taken for investigation. Upon boiling with sodium carbonate, 1.73 per cent of silica went into solution. From previously ignited heulandite, only 1.14 per cent was extracted. No silica, therefore, was liberated upon ignition, and a hydrous metasilicate formula for the mineral seems to be improbable. Only one lot of the ammonium 
chloride derivative was prepared, and its composition, together with that of the heulandite, is given below.

\begin{tabular}{|c|c|c|}
\hline & Beulandite. & $\begin{array}{l}\text { Ammonium } \\
\text { salt. }\end{array}$ \\
\hline $\mathrm{SiO}_{2} \ldots \ldots$ & 57.10 & 61.24 \\
\hline $\mathrm{Al}_{2} \mathrm{O}_{3} \ldots \ldots$ & 16.82 & 18.00 \\
\hline MgO $\ldots \ldots \ldots \ldots \ldots \ldots$ & .07 & - \\
\hline $\mathrm{CaO} \ldots$ & 6.95 & 2.56 \\
\hline SrO $\ldots \ldots \ldots$ & .46 & $\ldots$ \\
\hline $\mathrm{Na}_{2} \mathrm{O}$ & 1.25 & .60 \\
\hline $\mathbf{K}_{2} \mathbf{O}_{\ldots} \ldots \ldots \ldots$ & .42 & \} \\
\hline $\mathrm{NH}_{3} \ldots \ldots \ldots \ldots$ & {$[\ldots \ldots \ldots \ldots$} & 4.42 \\
\hline $\mathrm{H}_{2} \mathrm{O}$ at $100^{\circ} \ldots \ldots \ldots \ldots$ & 3.61 & 13.63 \\
\hline $\mathrm{H}_{2} \mathrm{O}$ above $100^{\circ} \ldots \ldots$ & 13.00 & 10.00 \\
\hline & 99.68 & 100.45 \\
\hline
\end{tabular}

Here, again, we have the same kind of transformation as before, but rather less complete than in the case of stilbite. That the ammonium taken up is equivalent to the bases removed is shown by a study of the ratios. Ignoring water and the soluble silica, the heulandite ratios are as follows:

or, uniting bases,

$$
\mathrm{R}_{48}^{\prime} \mathrm{R}_{130}^{\prime \prime} \mathrm{Al}_{330} \mathrm{Si}_{923} \mathrm{O}_{2495}
$$

$$
\mathrm{R}^{\prime \prime}{ }_{154} \mathrm{Al}_{330}\left(\mathrm{Si}_{3} \mathrm{O}_{8}\right)_{300}\left(\mathrm{SiO}_{4}\right)_{24} \text {. }
$$

Again simplifying, this becomes

or very nearly $1: 2: 2$, as in stilbite.

$$
\mathrm{R}^{\prime \prime}{ }_{154} \mathrm{Al}_{330} \mathrm{X}_{321}
$$

Similarly discussed, the ammonium salt gives the ratios

equivalent to

$$
\mathrm{R}_{270}^{\prime} \mathrm{Ca}_{46} \mathrm{Al}_{352} \mathrm{Si}_{1021} \mathrm{O}_{2746}
$$

$$
\mathrm{R}_{362}^{\prime} \mathrm{Al}_{352} \mathrm{X}_{353} \text {, or } 1: 1: 1 \text {. }
$$

In both cases the orthosilicate molecules are few, and the compounds approximate to trisilicates very closely.

CHABAZITE.

Characteristic flesh-colored crystals from Wassons Bluff, Nova Scotia. The analysis and fractional water determinations are-

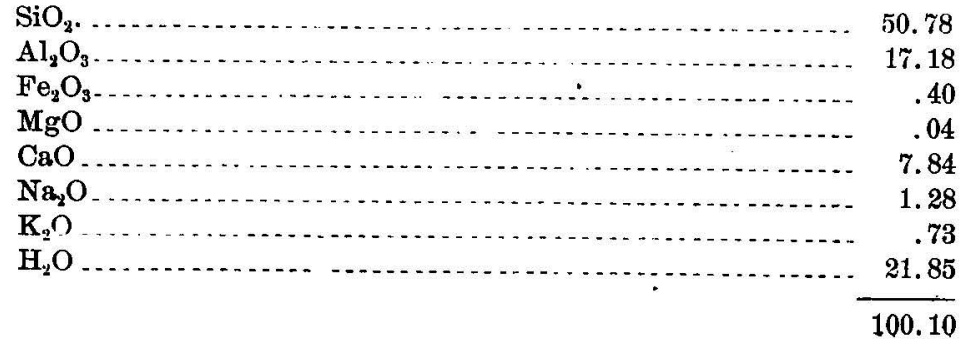


Fractional water.

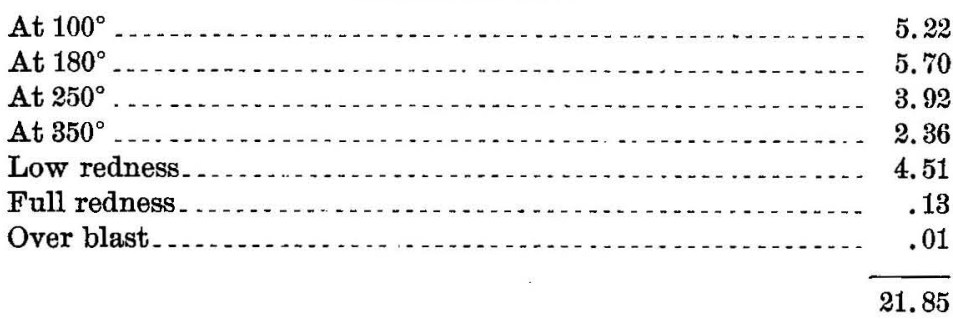

The unignited mineral, upon boiling with sodium carbonate, gave 0.86 per cent of soluble silica. After ignition only 0.53 per cent was soluble. Here again no silica is liberated by calcination, and metasilicate formulæ may be disregarded.

Two samples of the ammonium chloride derivative were prepared, which after thorough washing were dried at $40^{\circ}$ to $50^{\circ}$. As in the case of stilbite, small quantities of chlorine appear in the compound, not removable by washing. The amount of change effected is also somewhat less than with stilbite, and about the same as with heulandite. The analyses of the two samples are subjoined, with the remaining alkali all reckoned as soda:

\begin{tabular}{|c|c|c|}
\hline & A. & B. \\
\hline $\mathrm{SiO}_{2}$ & 55.88 & 56.09 \\
\hline $\mathrm{Al}_{2} \mathrm{O}_{3}$ & 19.15 & 19.49 \\
\hline $\mathrm{CaO}$ & 2.25 & 2.01 \\
\hline $\mathrm{Na}_{2} \mathrm{O}\left(\mathrm{K}_{2} \mathrm{O}\right)$ & .35 & .24 \\
\hline $\mathrm{NH}_{3}$ & 4.64 & 4.83 \\
\hline $\mathrm{H}_{2} \mathrm{O}$ & 16.57 & 16.01 \\
\hline \multirow[t]{2}{*}{$\mathrm{Cl} 1 \ldots \ldots \ldots \ldots \ldots \ldots$} & .95 & 1.35 \\
\hline & 99.79 & 100.02 \\
\hline \multirow[t]{2}{*}{ Less 0 . } & .21 & .30 \\
\hline & 99.58 & 99.72 \\
\hline
\end{tabular}

In B, 1.50 per cent of soluble silica was found. After ignition this was reduced to 1.12 per cent. No liberation of silica accompanies the splitting off of water and ammonia.

Upon studying the molecular ratios for chabazite and its derivative, relations appear precisely like those found for stilbite and heulandite. For chabazite itself, rejecting water and the 0.86 per cent of soluble silica, we have

$$
\mathrm{R}_{58}^{\prime} \mathrm{Ca}_{141} \mathrm{Al}_{340} \mathrm{Si}_{832} \mathrm{O}_{2344},
$$

or, consolidating soda with lime,

$$
\mathrm{Ca}_{170} \mathrm{Al}_{340}\left(\mathrm{Si}_{3} \mathrm{O}_{8}\right)_{246}\left(\mathrm{SiO}_{4}\right)_{94} \text {. }
$$

9506-No. $2.07-02-3$ 
One step further and this becomes

$$
\mathrm{Ca}_{170} \mathrm{Al}_{340} \mathrm{X}_{340}=1: 2: 2 \text {. }
$$

Treating derivative " $\mathrm{B}$ " in the same way, and ignoring chlorine as an unexplained impurity, the analysis gives

$$
\left(\mathrm{NH}_{4}\right)_{284} \mathrm{Na}_{8} \mathrm{Ca}_{35} \mathrm{Al}_{382}\left(\mathrm{Si}_{3} \mathrm{O}_{8}\right)_{266}\left(\mathrm{SiO}_{4}\right)_{112}
$$

or, consolidating bases as before,

$$
\mathrm{R}_{362}^{\prime} \mathrm{Al}_{382} \mathrm{X}_{378}=1: 1: 1 \text { nearly. }
$$

The assumption of commingled ortho- and trisilicate molecules conforms to Streng's theory of the constitution of chabazite.

\section{THOMSONITE.}

The compact-fibrous variety from Table Mountain, near Golden, Colo. Analytical data as follows:

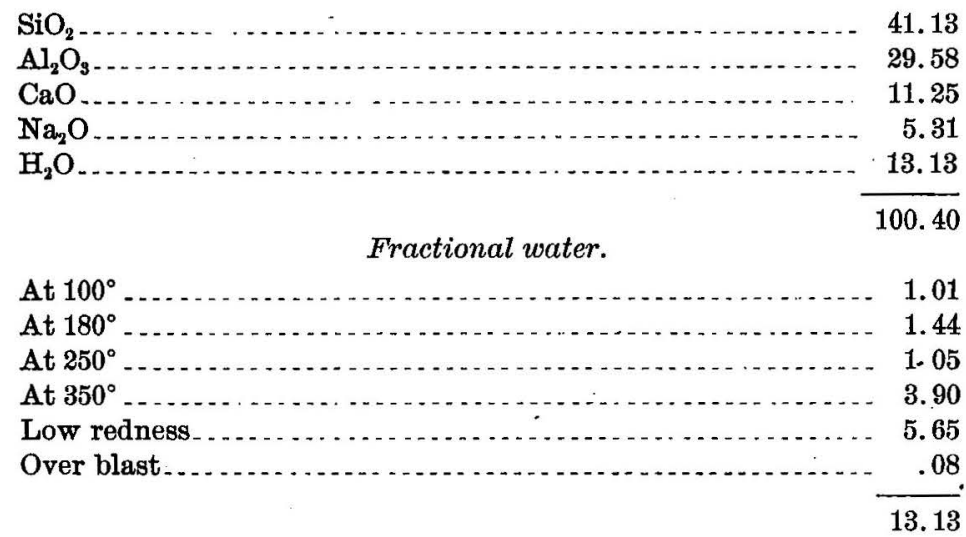

Before ignition the mineral yielded 0.45 per cent of silica to sodium carbonate solution. After ignition 0.68 per cent was soluble. The difference is trifling.

Two samples of the ammonium chloride derivative were prepared.

\begin{tabular}{|c|c|c|}
\hline & A: & B. \\
\hline $\mathrm{SiO}_{2} \ldots \ldots \ldots$ & 42.41 & 42.65 \\
\hline $\mathrm{Al}_{2} \mathrm{O}_{3}$ & 30.50 & 31.34 \\
\hline $\mathrm{CaO}$ & 10.00 & 9.23 \\
\hline $\mathrm{Na}_{3} \mathrm{O}$ & 2.63 & 2.48 \\
\hline $\mathrm{NH}_{3} \ldots \ldots$ & 2.45 & 2.67 \\
\hline \multirow{2}{*}{$\mathrm{H}_{3} \mathrm{O} \ldots \ldots \ldots$} & 11.96 & 11.81 \\
\hline & 99.95 & 100.18 \\
\hline
\end{tabular}
In $\mathrm{A}$ the heating was only to $300^{\circ}$, in $\mathrm{B}$ to $350^{\circ}$. Analyses of the leached products gave the following results: 
In A, 1.80 per cent of soluble silica was found.

In this case the amount of change is very much less than with the zeolites previously examined. Little lime was removed, and only about half of the soda. Both samples were prepared with six hours of heating in the sealed tube, and it seemed to be desirable to determine whether a more prolonged treatment would produce any greater effect. Accordingly a third lot of thomsonite was mixed with ammonium chloride and heated in a sealed tube to $350^{\circ}$ for twenty-four hours. The leached product contained 3.40 per cent of ammonia, a distinct increase over the other findings, although the amount of transformation into an ammonium salt was still only moderate.

We have already seen that stilbite, heulandite, and chabazite approximate more or less nearly to trisilicates in their composition. Thomsonite, however, is essentially an orthosilicate, with variable admixtures of trisilicate molecules. In the example under consideration, ignoring water and soluble silica, the molecular ratios give this formula:

or, condensing,

$$
\begin{gathered}
\mathrm{Na}_{172} \mathrm{Ca}_{201} \mathrm{Al}_{580}\left(\mathrm{Si}_{3} \mathrm{O}_{8}\right)_{50}\left(\mathrm{SiO}_{4}\right)_{528} \\
\mathrm{R}^{\prime \prime}{ }_{287} \mathrm{Al}_{580} \mathrm{X}_{578}=1: 2: 2 .
\end{gathered}
$$

Here the acid radicles are ten-elevenths orthosilicate. Ammonium derivative A, similarly computed, gives first-

$$
\left(\mathrm{NH}_{4}\right)_{144} \mathrm{Na}_{84} \mathrm{Ca}_{178} \mathrm{Al}_{598}\left(\mathrm{Si}_{3} \mathrm{O}_{8}\right)_{41}\left(\mathrm{SiO}_{4}\right)_{554}
$$

or, uniting univalent bases with lime,

$$
\mathrm{R}^{\prime \prime}{ }_{292} \mathrm{Al}_{598} \mathrm{X}_{595}=1: 2: 2 \text {; }
$$

the fundamental ratios being practically unchanged.

It will be observed that in all of these computations of formulæ we have assumed that all the water is "zeolitic;" that is, independent of the true chemical molesules. This question, however, needs to be separately investigated for each individual species. While the assumption is valid for some of these minerals, it is not necessarily valid for all. The real chemical differences between the zeolites are yet to be determined; our work merely proves that ammonium compounds are formed, completely in some cases, partially in cthers. The research should be extended to cover all the zeolites; but this task we must leave to other investigators.

\section{LAUMONTITE.}

Upon this species only one rather crude experiment has been tried, and that upon material of unknown origin. The mineral was heated with ammonium chloride in a sealed tube as usual, and then leached with water. 4.001 per cent of lime and 0.35 of soda were extracted, and in the residue 3.95 per cent of ammonia was found. Laumontite, therefore, behaves much like the other zeolites, and is only partially transformed into an ammonium compound. 


\section{PECTOLITE.}

The pectolite which was chosen for examination was the well-known radiated variety from Bergen Hill, N. J. The mineral was in long white needles, and apparently quite pure, but the analysis shows that it contained some carbonate as an impurity. Enough of the material was ground up to furnish a uniform sample for the entire series of experiments, and the work properly began with a complete analysis. The results obtained are as follows:

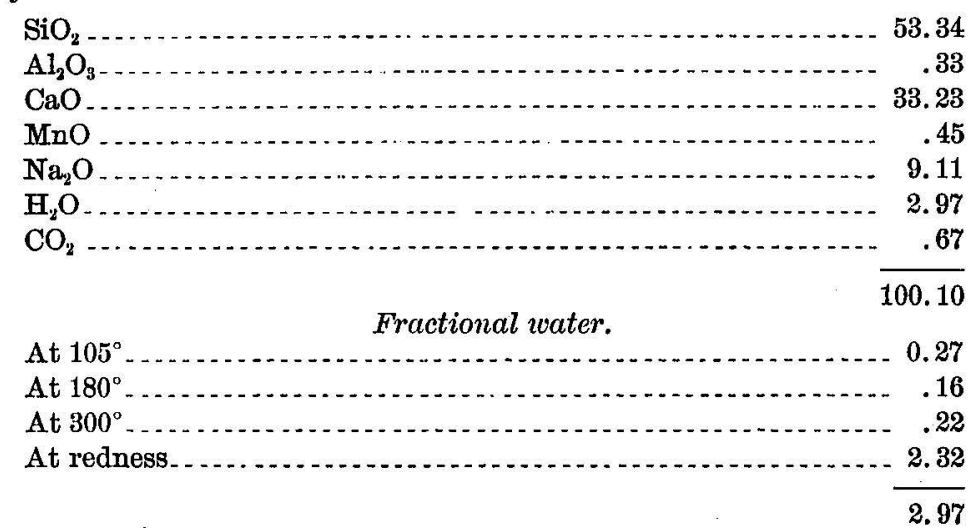

All of the water was given off at a barely visible red heat, and the figures show that practically all of it is constitutional-a fact which perhaps hardly needed reverification. The analysis gives the accepted formula for pectolite,

$$
\mathrm{HNaCa}_{2} \mathrm{Si}_{3} \mathrm{O}_{9} \text {. }
$$

Does this represent, as is commonly assumed, a true metasilicate? If it does, we should expect that ignition would split off silica proportional to the acid hydrogen, or one-sixth of the total amount. To answer this question several portions of the pectolite were sharply ignited, to complete dehydration, and then boiled each for fifteen minutes with a solution of sodium carbonate containing 250 grams to the liter. In the extract so obtained the silica was determined, and the three experiments gave the following percentages:

$$
\begin{array}{r}
8.96 \\
8.67 \\
8.42 \\
\hline \text { Mean, } 8.68
\end{array}
$$

One-sixth of the total silica is 8.89 per cent, and the experiments, therefore, justify the original expectation. The belief that pectolite is a metasilicate is effectively confirmed.

Upon the unignited pectolite the sodium carbonate solution has a slow decomposing action, both silica and bases being withdrawn. In two experiments fifteen minutes of boiling extracted 2.07 and 2.55 per cent of silica, and by a treatment lasting four days 4.80 per cent 
was taken out. With water alone similar results were obtained, the action being so rapid, although relatively slight, that pectolite, moistened, gives an immediate and deep coloration with phenol phthalein. By boiling the powdered pectolite with distilled water alone, 1.65 per cent of silica was brought.into solution, and the ignited mineral, similarly treated for fifteen minutes, gave 1.78 per cent. The extraction in these cases is really an extraction of alkaline silicate, as the two following experiments prove. In A the unignited pectolite was boiled for fourteen hours with distilled water, and in $\mathrm{B}$ the mineral after ignition was subjected to like treatment for four hours. The dissolved matter in each case was determined, with the subjoined results:

\begin{tabular}{|c|c|c|}
\hline Extracted. & A. & B. \\
\hline $\mathrm{SiO}_{2 \ldots} \ldots$ & 2.98 & 3.03 \\
\hline $\mathrm{CaO}$ & .30 & .10 \\
\hline \multirow[t]{2}{*}{$\mathrm{Na}_{2} \mathrm{O}$} & .81 & 1.50 \\
\hline & 4.09 & 4.63 \\
\hline
\end{tabular}

In $\mathbf{A}$ no simple ratio appears, but in $\mathrm{B}$ the extracted silicate approximates very nearly to the salt $\mathrm{Na}_{2} \mathrm{Si}_{2} \mathrm{O}_{5}$. In each instance the ratios vary widely from those of the original mineral, showing that actual decomposition and not a solution of the pectolite, as such, has occurred.

Schneider and Clarke, ${ }^{a}$ in their first experiments upon the ammonium chloride reaction, treated pectolite from Bergen Hill three times successively with the reagent and then leached out with water. In the solution 20.50 per cent of lime and 6.95 of soda were found, showing that a very considerable decomposition had taken place, but the residue was not examined. In a preliminary experiment by the sealed tube method we found that 20.72 per cent of lime and 6.46 of soda were taken out, while 1.44 per cent of ammonia was retained by the residue. That is, two-thirds of the bases, approximately, had been converted into chlorides by the reaction. The open crucible and the sealed tube gave essentially the same results, although the retention of ammonia was not noticed by Schneider and Clarke.

In order to obtain further light upon pectolite we continued our experiments with the sealed tube method, and have obtained very variable results. All of the heatings with ammonium chloride were conducted at $350^{\circ}$, and the pectolite used was from the same Bergen Hill specimen which served us for our previous work. Our data are as follows, including for convenience of comparison the preliminary experiment which was cited above:

A. Heated six hours. On leaching, 20.72 per cent of lime, 6.46 soda, and 0.11 alumina dissolved. The residue contained 1.44 per cent of ammonia.

u Bull. U. S. Geol. Survey No. 113, p. 34, 1893. 
B. Heated six hours. 20.10 per cent lime and 5.80 of soda extracted. 1.45 per cent ammonia in the residue. The residue was also examined for silica soluble in 25 per cent sodium carbonate solution (on fifteen minutes boiling), and 43.38 per cent was found.

C. Heated six hours. Soluble portion neglected. The residue contained 2.23 per cent of ammonia and 61.79 per cent of soluble silica. The full analysis of this residue is given later.

D. Heated ten hours. A complex breaking up of the pectolite took place, and leaching with water extracted the following percentages:

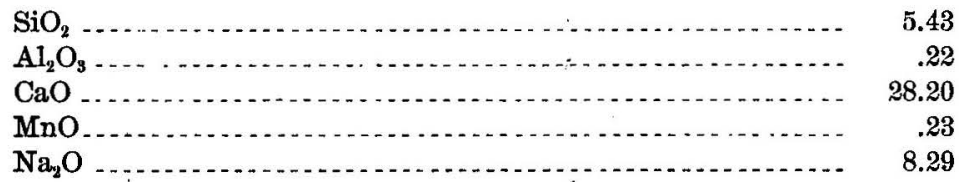

The residue from this leaching contained 39.63 of soluble silica, but ammonia was not determined.

These results are so irregular that definite conclusions can hardly be drawn from them. $A$ and $B$ agree fairly with each other, and also with the earlier work of Schneider and Clarke. C contains more ammonia, but differs widely from $B$ as to the amount of soluble silica in the residue. $\mathrm{D}$, which represents a long heating, indicates a more complete reaction than was observed in either of the other cases.

An ammonium compound, however, is 'evidently formed during the reaction, although its precise nature can not be determined from the evidence now in hand. Something may be inferred from the following figures, which are to be summarized thus: First, we reproduce from our earlier paper the analysis of the pectolite itself. Secondly, we give the analysis of the insoluble residue obtained in experiment C. The third column of figures is obtained by subtracting from the second column 61.79 of solnble silica and 1.18 of hygroscopic water, and recalculating the remainder to 100 per cent. The fourth column contains the molecular ratios calculated from the third.

\begin{tabular}{|c|c|c|c|c|}
\hline & Pectolite: & $\begin{array}{l}\text { Residue } \\
\text { found. }\end{array}$ & $\begin{array}{l}\text { Residue } \\
\text { reduced. }\end{array}$ & Ratios. \\
\hline $\mathrm{SiO}_{2} \ldots \ldots \ldots \ldots \ldots$ & 53.34 & 75.98 & 37.74 & 0.629 \\
\hline $\mathrm{Al}_{2} \mathrm{O}_{3} \ldots \ldots$ & .33 & .08 & .19 & .002 \\
\hline $\mathrm{CaO} \ldots \ldots \ldots$ & 33.23 & 9.56 & 25.43 & .454 \\
\hline $\mathrm{MnO} \ldots \ldots . . . . .$. & .45 & .24 & .63 & .009 \\
\hline $\mathrm{Na}_{2} \mathrm{O}$ & 9.11 & 1.84 & 4.89 & .079 \\
\hline $\mathrm{NH}_{3}$ & $\ldots$ & 2.23 & 5.93 & .349 \\
\hline $\mathrm{H}_{2} \mathrm{O}$ at $100^{\circ} \ldots$ & .27 & 1.18 & & \\
\hline $\mathrm{H}_{8} \mathrm{O}$ above $100^{\circ}$ & 2.70 & 9.47 & 25.19 & 1.399 \\
\hline \multirow[t]{2}{*}{$\mathrm{CO}_{2}, \ldots \ldots$} & .67 & $\ldots \ldots$ & n. & \\
\hline & 100.10 & 100.58 & 100.00 & \\
\hline
\end{tabular}


These ratios roughly suggest the formation of a salt approximating in composition to the formula $\mathrm{R}_{2}^{\prime} \mathrm{Ca}_{2} \mathrm{Si}_{3} \mathrm{O}_{9} \cdot 6 \mathrm{H}_{2} \mathrm{O}$, in which $\mathrm{R}^{\prime}$ is about two-thirds ammonium and one-third sodium. The large amount of water found was doubtless absorbed during the process of leaching. Pectolite itself has the formula $\mathrm{NaHCa}_{2} \mathrm{Si}_{3} \mathrm{O}_{9}$, so that the existence of a hydrous ammonium pectolite is indicated; a conclusion which is probable but not proved. The reaction between pectolite and ammonium chloride is possibly simple at first, but followed by or entangled with secondary changes which obscure the results. The experiments are interesting, however, as showing how widely pectolite differs from the other minerals which we have studied, as regards the ammonium chloride reaction.

\section{WOLLASTONITE.}

The only data relative to the action of ammonium chloride upon wollastonite are those given in the original paper by Schneider and Clarke, but on account of the close relationship between this species and pectolite it seems desirable to reproduce the record here. The mineral studied was from Diana. N. Y., and it had the subjoined composition :

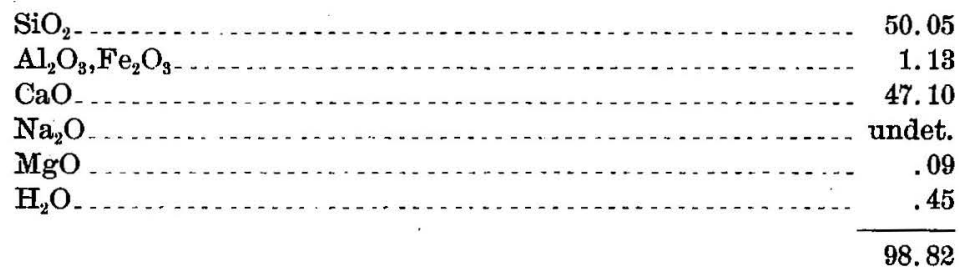

After two heatings.with ammonium chloride in an open crucible, 36.98 per cent of lime became soluble in water. In other words, a very notable decomposition had occurred, as in the case of pectolite. Since wollastonite is an anhydrous mineral, this result shows that the reaction does not depend upon the presence of hydroxyl.

\section{APOPHYLLITE.}

Upon this species only one rather crude experiment was made, and that with material of unknown locality. Heated with ammonium chloride in a sealed tube, it gave up, on leaching with water, 21.59 per cent of lime and 5.18 of potassa. The residue contained only 0.79 per cent of ammonia. Evidently the mineral, like pectolite and wollastonite, is largely decomposed by the reagent; but it is uncertain whether any regular ammonium compound is formed. It must be remembered that apophyllite sometimes contains small quantities of ammonia, and hence it seems that a more complete investigation of it is desirable. 


\section{DATOLITE.}

The compact, porcelain-like datolite from Lake Superior. This was heated in a sealed tube with ammonium chloride in the usual way. After leaching the product with water, the washed residue contained 91.09 per cent of silica and 1.17 of ammonia. Evidently the datolite molecule had been thoroughly broken down, with nearly complete removal of the bases and the boric acid. The significance of the retained ammonia, however, is not clear.

\section{ELAOLITE.}

On account of their interest as rock-forming minerals, the three species nephelite var. elæolite, sodalite, and cancrinite were studied consecutively and with some reference to one another. The elæolite was the characteristic material from the elæolite-syenite of Litchfield, Me., and had the following composition:

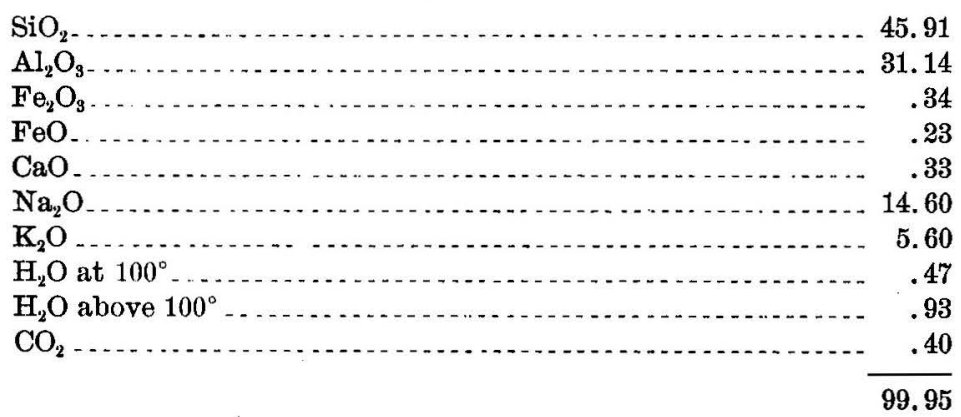

Five grams of mineral were thoroughly mixed with 20 grams of ammonium chloride by long grinding in an agate mortar, and then heated for six hours in a sealed tube to $350^{\circ}$. Even during the grinding a strong smell of ammonia was noticeable, and upon opening the sealed tube after heating, a slight pressure of ammonia gas was observed. On extraction with water the following bases passed into solution:

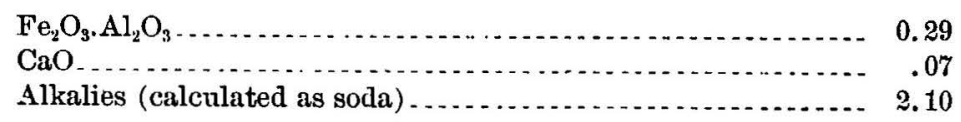

The residue from the leach water was dried at $50^{\circ}$, and then found to contain 0.92 per cent of ammonia. These figures confirm those obtained in a much less eareful preliminary experiment, and show that elæolite is but slightly affected by the reagent. 


\section{CANCRINITE.}

The material studied was the well-known bright yellow cancrinite from Litchfield, Me., and an analysis of it gave the following results:

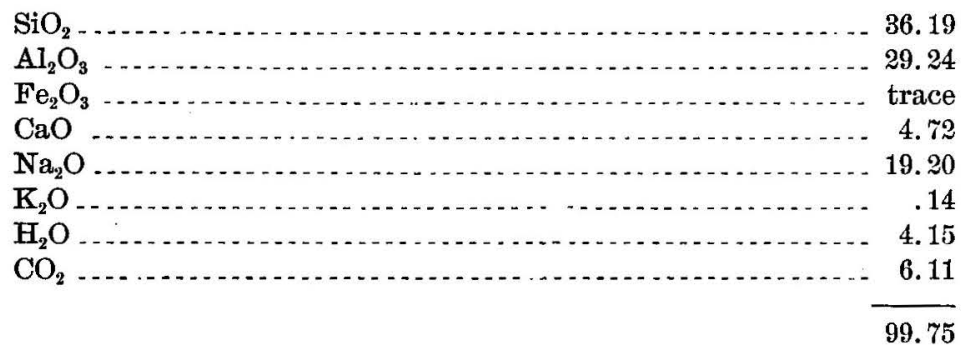

Upon boiling the powdered mineral for fifteen minutes with the standard solution of sodium carbonate, $0.55 \mathrm{per}$ cent of silica went into solution. After ignition, only 0.32 per cent was soluble. No silica, therefore, had been split off by heating.

With ammonium chloride two experiments were made. In each case the mineral was intimately ground with four times its weight of the chloride, and heated to $350^{\circ}$ in a sealed tube for four hours. During grinding a strong smell of ammonia was noticed, and still more was given off when the tubes were opened. The products were leached with water, and the thoroughly washed residues were analyzed, as follows:

\begin{tabular}{|c|c|c|}
\hline & A. & B. \\
\hline $\mathrm{SiO}_{2}$ & 37.48 & 37.51 \\
\hline $\mathrm{Al}_{2} \mathrm{O}_{3}$ & 31.23 & 31.98 \\
\hline $\mathrm{CaO}$ & 5.10 & 5.30 \\
\hline $\mathrm{Na}_{2} \mathrm{O}\left(+\mathrm{K}_{2} \mathrm{O}\right)$ & 7.78 & 7.53 \\
\hline $\mathrm{NH}_{3} \ldots \ldots$ & 4.73 & 3.77 \\
\hline $\mathrm{H}_{2} \mathrm{O}$ at $100^{\circ}$ & 1.29 & \\
\hline $\mathrm{H}_{2} \mathrm{O}$ above $100^{\circ}$ & 12.24 & \\
\hline \multirow[t]{2}{*}{$\mathrm{CO}_{2}$} & none & none \\
\hline & 99.85 & 100.57 \\
\hline
\end{tabular}

In the wash water from product $B, 11.73$ per cent of the original soda was found, with no lime, and 0.16 per cent of silica and alumina. Somewhat less than two-thirds of the soda had been taken out. The lime seems to be much more stably combined, and water was taken up, probably in the process of leaching. The carbonic acid of the cancrinite had been completely eliminated. 
Apparently, if the product of the reaction is a definite compound, the effect of the ammonium chloride has been to transform the cancrinite into a zeolitic body, approximating roughly to the general formula

$$
\mathrm{R}^{1} \mathrm{Al} \mathrm{SiO} \mathrm{Si}_{4} \cdot \mathrm{H}_{2} \mathrm{O}
$$

but with a small excess of the univalent bases. Analysis A, adjusted by rejecting the 1.29 per cent of hygroscopic water, and recalculation of the remainder to 100 per cent, assumes the following form and gives the appended ratios:

\begin{tabular}{|c|c|c|}
\hline & $\begin{array}{l}\text { Analysis re- } \\
\text { duced. }\end{array}$ & Ratios. \\
\hline $\mathrm{SiO}_{2} \ldots \ldots$ & 38.03 & 0.634 \\
\hline $\mathrm{Al}_{2} \mathrm{O}_{3}$ & 31.69 & .311 \\
\hline $\mathrm{CaO}$ & 5.17 & .093 \\
\hline $\mathrm{Na}_{2} \mathrm{O}$ & 7.89 & .127 \\
\hline $\mathrm{NH}_{3} \ldots \ldots$ & 4.80 & .282 \\
\hline \multirow[t]{2}{*}{$\mathrm{H}_{2} \mathrm{O} \ldots \ldots$} & 12.42 & .690 \\
\hline & 100.00 & \\
\hline
\end{tabular}

The substance is evidently not absolutely pure, a condition which might have been expected. Any closer attempt at precise formulation would therefore be useless. It most nearly resembles, among the products which we have obtained, the ammonium derivative of thomsonite.

SODALITE.

Dark-blue sodalite from Kicking Horse Pass, British Columbia. Analysis as follows:

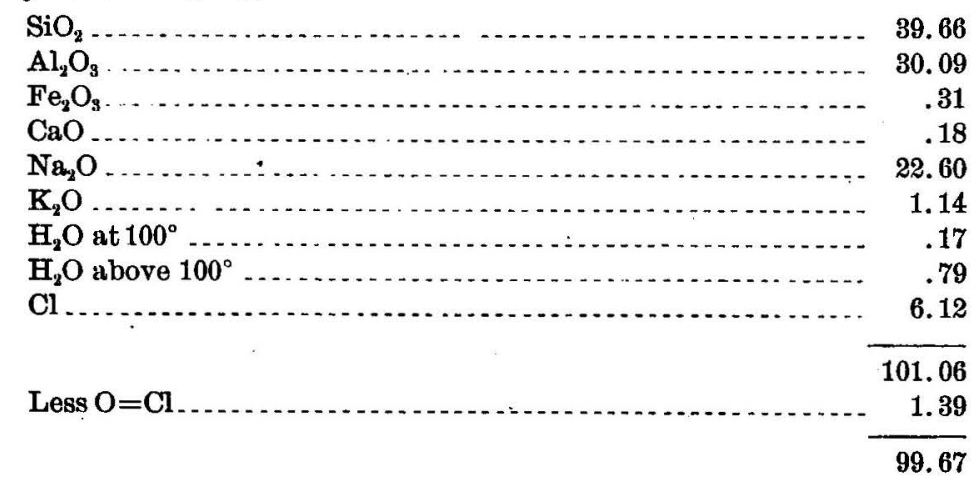

With ammonium chloride two preparations were made, both by the sealed-tube method at $30^{\circ}$. In $A$ the heating lasted twenty-four hours; and in B six hours. From residue A, by leaching with water, 2.96 per cent of alkali, reckoned as soda, was extracted; and from $B$, 
3.53 per cent. In the washed residues the following determinations were made, but eomplete analysis seemed to be unnecessary.

\begin{tabular}{|c|c|c|}
\hline & A. & B. \\
\hline $\mathrm{SiO}_{2}$ & 39.33 & 40.00 \\
\hline $\mathrm{Al}_{2} \mathrm{O}_{3}\left(\mathrm{Fe}_{2} \mathrm{O}_{3}\right)$ & 31.40 & 32.34 \\
\hline $\mathrm{CaO}$ & .20 & - \\
\hline $\mathrm{Na}_{2} \mathrm{O}\left(\mathrm{K}_{2} \mathrm{O}\right)$ & 20.86 & $\ldots$ \\
\hline $\mathrm{NH}_{\mathbf{3}}$ & .45 & .72 \\
\hline Cl & 5.92 & $\ldots$ \\
\hline
\end{tabular}

Evidently the amount of change was slight, and no definite ammonium derivative had been formed.

In one way these results shed some light upon the constitution of sodalite. According to Lemberg and his pupils the mineral is a double salt, a molecular compound of sodium chloride with a silicate like nepheline. If this view were correct sodium and chlorine should be removed together by the action of a decomposing reagent. We find, however, that about 3 per cent of soda was removed from sodalite in forming residue $A$, while practically all of the chlorine remains behind. So far, then, the evidence is adverse to the view just cited and favorable to that of Brögger, which assigns the mineral, as an atomic compound, to a place in the garnet group.

On the other hand, sodium chloride may be volatilized from sodalite by prolonged heating. Two portions of the mineral were each heated for four hours over a blast-lamp flame, losing 10.80 and 10.72 per cent, respectively. The chlorine in the mineral, 6.12 per cent, corresponds to 10.08 per cent of $\mathrm{NaCl}$; to this must be added the 0.91 of water found, making a total possible loss of 11.04 per cent. In the residue from the first lot ignited 0.20 of chlorine was found, so that the volatilization of sodium chloride had been almost complete. This reaction, however, taking place at a very high temperature, may be only a result of metathesis, and not by any means a proof that sodium chloride, as such, is an essential constituent of sodalite. The evidence derived from the ammonium chloride reaction is entitled to the greater weight.

\section{THE FELDSPARS.}

The results which we have obtained with these important rockforming minerals are interesting only in so far as they show a trifling sensitiveness on the part of the several species toward dissociating ammoniurn chloride. The action upon them is slight, and ammonium derivatives do not seem to be formed. The data may be briefly summarized as follows:

Orthoclase.-From southeastern Pennsylvania, exact locality unknown. Quite pure cleavage masses. Heated for six hours with 
ammonium chloride to $350^{\circ}$ in a sealed tube, and leached with water, 1.52 per cent of $\mathrm{KCl}$ went into solution. The residue, dried at $50^{\circ}$, contained 0.20 per cent of ammonia.

Oligoclase.-The transparent variety from Bakersville, N. C. Treated like the orthoclase. In the leach water 0.96 per cent of lime and 2.71 of soda were found. The air-dried residue contained 1.47 per cent of ammonia. It is barely possible that in this case an ammonium derivative may have been produced, but the data are not positive enough to warrant any definite conclusion.

Albite.-Well-crystallized and very pure material from Amelia Courthouse, Va. Treated like the two preceding feldspars. Upon leaching, 0.12 per cent of lime and 0.84 of soda went into solution. In the residue, dried at $50^{\circ}, 0.32$ per cent of ammonia was retained.

\section{OLIVINE.}

Green, transparent pebbles from near Fort Wingate, N. Mex. Examined by Schneider and Clarke, who employed only the open crucible method. By treatment with ammonium chloride only 0.44 per cent of magnesia was rendered soluble in water-i. e., converted into magnesium chloride. In view of the ready solubility of this mineral in even weak aqueous acids, this lack of sensitiveness to ammonium chloride is somewhat remarkable.

\section{ILVAITE.}

This rare mineral was found by Mr. Waldemar Lindgren at the Golconda mine, South Mountain, Owyhee County, Idaho. It occurs in jet black masses and occasional rough crystals, embedded in quartz or calcite, and intimately associated with two other minerals which appear to be garnet and tremolite. Traces of pyrite also appear. The specific gravity of the ilvaite, as determined by Dr. Hillebrand, is 4.059 at $31^{\circ}$.

Upon grinding the powdered mineral with ammonium chloride in an agate mortar, a distinct smell of ammonia was noticeable. Three tubes of the mixture were heated to $350^{\circ}$, and one exploded because of the liberation of gas within. Upon opening the second and third tubes, a strong outrush of ammonia was observed. When the contents of these tubes were leached with water, large quantities of ferrous ehloride went into solution, which, rapidly oxidizing, formed a deposit of brownish hydroxide, and interfered serionsly with filtration. The greater part of the lime in the ilvaite was dissolved also. The washed residue, containing much ferric hydroxide, was partially analyzed, and enough data were obtained to show that a general breaking down of the ilvaite molecule had been effected. Apparently, also, small quantities of an ammonium derivative had been formed; 
but this point is uncertain. The original mineral was analyzed by Dr. W. F. Hillebrand, and his analysis, contrasted with that of the leached residue, is here given:

\begin{tabular}{|c|c|c|}
\hline & $\begin{array}{l}\text { Ilvaite (Hille- } \\
\text { brand). }\end{array}$ & $\begin{array}{c}\text { Residue } \\
\text { (Steiger). }\end{array}$ \\
\hline $\mathrm{SiO}_{2} \ldots \ldots \ldots$ & 29.16 & 43.01 \\
\hline $\mathrm{Al}_{2} \mathrm{O}_{3}$ & .52 & 4008 \\
\hline $\mathrm{Fe}_{2} \mathrm{O}_{3}$ & 20.40 & \\
\hline $\mathrm{FeO}$ & 29.14 & 8. 75 \\
\hline MnO $\ldots \ldots \ldots$ & 5.15 & .85 \\
\hline $\mathrm{CaO}$ & 13.02 & 2.25 \\
\hline MgO & .15 & undet. \\
\hline $\mathrm{Na}_{2} \mathrm{O}$ & .08 & undet. \\
\hline $\mathrm{NH}_{3}$ & . & .88 \\
\hline $\mathrm{H}_{2} \mathrm{O}$ at $105^{\circ}$ & .15 & undet. \\
\hline $\mathrm{H}_{2} \mathrm{O}$ above $105^{\circ}$ & 2.64 & undet. \\
\hline $\mathrm{Cl}$ & ...... & (a) \\
\hline & 100.41 & 95.82 \\
\hline
\end{tabular}

$a$ Small amount.

In the leached residue from the third tube 21.37 per cent of soluble silica was found-silica which had been liberated during the reaction between the ilvaite and the ammonium chloride. In short, ilvaite behaves toward the reagent much like pectolite, and the product is a mixture of uncertain character. The evident instability of the ilvaite molecule may account for its rarity as a mineral species. Only exceptional conditions would favor its formation.

\section{RIEBECKITE(?).}

The results obtained with ilvaite made it desirable to study, for comparison, some other silicates of iron. Among these the mineral from St. Peters Dome, near Pikes Peak, Colorado, originally described by Koenig as arfvedsonite, but identified by Lacroix as near riebeckite, happened to be available. It was treated with ammonium chloride in the usual way and no presence of liberated gas was noticed when the tube was opened. On leaching the product with water, ferrous chloride went into solution and ferric hydroxide with some manganic hydroxide was deposited. In the leached mass 6.90 per cent of soluble silica was found, and in the wash water from the leaching there was 6.76 per cent of soda. According to Koenig's analysis the mineral contains 8.33 per cent of soda, so that a large portion of the total amount had been extracted. There was also, 
evidently, a considerable breaking down of the molecule, but no definite ammonium derivative had been formed. This is shown by the following analysis of the leached residue, which is contrasted with Koenig's published analysis ${ }^{a}$ of the original mineral in order to indicate the amount of change. In the third column of figures we give the amount of each constituent which could be dissolved out from the residue by treatment with hydrochloric acid.

\begin{tabular}{|c|c|c|c|}
\hline & $\begin{array}{l}\text { Riebeckite } \\
\text { (Koenig). }\end{array}$ & $\begin{array}{c}\text { Residue } \\
\text { (Steiger). }\end{array}$ & $\begin{array}{c}\text { Soluble } \\
\text { portion. }\end{array}$ \\
\hline $\mathrm{SiO}_{2} \ldots \ldots$ & 49.83 & 67.54 & \\
\hline $\mathrm{TiO}_{2}$ & 1.43 & $\ldots$ & \\
\hline $\mathrm{ZrO}_{2}$ & .75 & 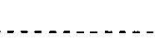 & - . . . \\
\hline $\mathrm{Fe}_{2} \mathrm{O}_{3}$ & 14.87 & 21.28 & 15.74 \\
\hline FeO & 18.86 & 4.94 & 4.94 \\
\hline MnO $\ldots \ldots$ & 1.75 & .64 & .64 \\
\hline MgO $\ldots \ldots \ldots$ & .41 & none & -. \\
\hline $\mathrm{CaO}$ & $\ldots . .$. & trace & $\ldots$ \\
\hline $\mathrm{Na}_{2} \mathrm{O}$ & 8.33 & 1.04 & \\
\hline $\mathbf{K}_{2} \mathbf{O}$ & 1.44 & & \\
\hline $\mathrm{NH}_{3} \ldots \ldots$ & ..... & .53 & .53 \\
\hline $\mathrm{H}_{2} \mathrm{O} \ldots$ & .20 & 3.33 & \\
\hline \multirow[t]{2}{*}{$\mathrm{Cl} \ldots \ldots$} & -.... & trace & (n) \\
\hline & 97.87 & 99.30 & $\cdots$ \\
\hline
\end{tabular}

The residue is evidently a mixture of free silica and ferric hydrate with probably at least two silicates, one soluble, the other insoluble in hydrochloric acid. The reaction itself is noteworthy because of the fact that the original mineral is but slightly attacked when boiled with strong hydrochloric acid. The other minerals so far studied by us are all easily decomposable by acids, while this one is quite refractory. The energetic character of the ammonium chloride reaction is thus strongly emphasized.

\section{AEGIRITE.}

Material from the well-known locality at Magnet Cove, Arkansas. Not absolutely pure, but somewhat contaminated by ferric hydroxide. This impurity is evident in a discussion of the ratios furnished by the analysis, but is not serious. It does not affect the problems under consideration. By heating with ammonium chloride the mineral was only slightly changed. In the leach water from the product there 
were 1.66 per cent $(\mathrm{AlFe})_{2} \mathrm{O}_{3}, 0.51 \mathrm{CaO}$ and $1.18 \mathrm{Na}_{2} \mathrm{O}$. Analyses as follows: $A$ of the ægirite, $B$ of the air-dried, leached residue.

\begin{tabular}{|c|c|c|}
\hline & A. & B. \\
\hline $\mathrm{SiO}_{2} \ldots \ldots \ldots \ldots$ & 50.45 & 51.83 \\
\hline $\mathrm{Al}_{2} \mathrm{O}_{3} \ldots \ldots \ldots$ & 2.76 & 25,24 \\
\hline $\mathrm{Fe}_{2} \mathrm{O}_{3}$ & 23.42 & 20.24 \\
\hline FeO & 5.26 & 5.69 \\
\hline 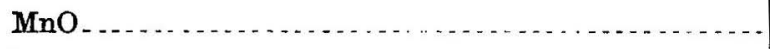 & .10 & $\ldots$. \\
\hline MgO $\ldots \ldots$ & 1.048 & 1.58 \\
\hline $\mathrm{CaO}$ & 5.92 & 5.74 \\
\hline $\mathrm{Na}_{2} \mathrm{O}$ & 9.84 & 907 \\
\hline $\mathrm{K}_{2} \mathrm{O}$ & .24 & 9.06 \\
\hline $\mathrm{NH}_{3}$ & & .26 \\
\hline $\mathrm{H}_{2} \mathrm{O}$ at $100^{\circ}$ & .15 & 90 \\
\hline \multirow[t]{2}{*}{$\mathrm{H}_{2} \mathrm{O}$ above $100^{\circ} \ldots \ldots$} & .40 & .30 \\
\hline & 100.02 & 100.31 \\
\hline
\end{tabular}

Of the silica in the residue 4.42 per cent was soluble in sodium carbonate solution. An ammonium derivative was not formed.

From these data we see that the three iron silicates are very differently attacked by ammonium chloride; ilvaite very strongly, riebeckite moderately, and ægirite but feebly. The ægirite is the most stable and at the same time the commonest of the three. A comparison of the rgirite analysis with that made by J. Lawrence Smith of material from the same region shows notable differences. The mineral evidently varies in composition, the variation depending upon the relative amounts of the two silicate molecules $\mathrm{FeNaSi}_{2} \mathrm{O}_{6}$ and $\mathrm{R}^{\prime \prime} \mathrm{SiO}_{3}$. Two samples taken from different parts of the same rock area are not necessarily identical in composition.

\section{CALAMINE.}

The simplest constitutional formula for calamine, the one which is generally accepted, represents it as a basic metasilicate,

$$
\mathrm{SiO}_{3}=(\mathrm{ZnOH})_{2} \text {. }
$$

In this the hydrogen is all combined in one way, and so, too, is the zinc. In all other possible formulæ, simple or complex, the hydrogen as well as the zinc must be represented as present in at least two modes of combination; a condition of which, if it exists, some evidence should be attainable. Our experiments upon calamine have had this point in view; and we have sought to ascertain whether water or zinc could be split off in separately recognizable fractions. Our results, in the main, have been negative, and tend toward the support of the 
usual formula; but the data are not conclusive, although they seem to be worthy of record.

The beautiful white calamine from Franklin, N. J., was selected for study, and gave the subjoined composition:

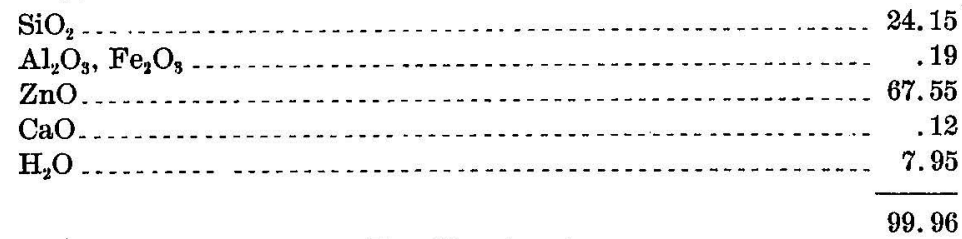

Fractional water.

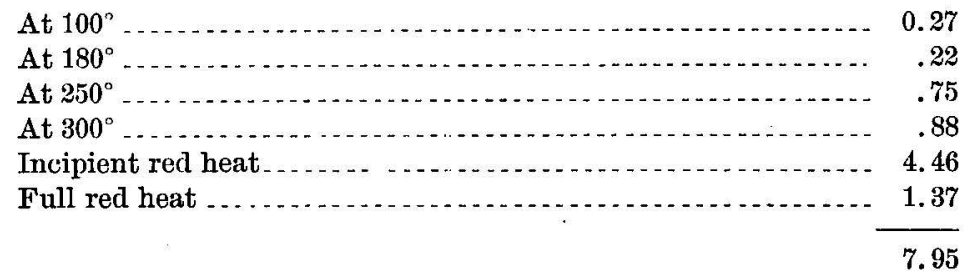

Here no clear and definite fractionation of the water is recognizable, at least of such a character as to suggest any other than the ordinary formula for calamine.

Upon boiling powdered calamine with water, practically nothing went into solution, but by boiling with the solution of sodium carbonate 0.25 per cent of silica was dissolved. After ignition at a red heat, only 0.14 per cent of silica became soluble in sodium carbonate; and after blasting, only 0.24 . In these experiments a very little zinc was dissolved also; but there was no evidence that any breaking up of the mineral into distinguishable fractions had occurred. In a hot 10 per cent solution of caustic soda both the fresh and the ignited calamine dissolve almost completely; but boiling with aqueous ammonia seems to leave the mineral practically unattacked. All experiments aiming to extract a definite fraction of zine while leaving a similar fraction behind resulted negatively.

By heating with dry ammonium chloride in an open crucible, calamine is vigorously attacked and gains in weight by absorption of chlorine. In two experiments the mineral was intimately mixed with three times its weight of powdered sal ammoniac and heated in an air bath for several hours to a temperature somewhat over $400^{\circ}$. A large part of the residue was soluble in water, and the percentage of this portion, together with the percentage increase in weight, is given below:

\begin{tabular}{l|l|l}
\hline & I. & II. \\
\hline Gain in weight $\ldots \ldots \ldots \ldots$ & 27.60 & 25.78 \\
Soluble in water......... & & \\
\end{tabular}


A conversion of calamine into the chlorhydrin $\mathrm{SiO}_{3}(\mathrm{ZnCl})_{2}$ would involve a gain in weight of 15.34 per cent. Complete conversion into $2 \mathrm{ZnCl}_{2}+\mathrm{SiO}_{2}$ implies an increase of 38.14 per cent. The figures given lie between these two, and are indefinite also for the reason that there was volatilization of zine chloride.

In two more experiments the calamine, mingled with three times and four times its weight of ammonium chloride, respectively, was heated for an hour and a half to bright redness in a combustion tube. The zinc chloride which was formed volatilized and was collected by suitable means for determination. It corresponded to 59.6 and 59.0 per cent of the original mineral, calculated as zinc oxide, which indicates a nearly complete decomposition of the calamine into $2 \mathrm{ZnCl}_{2}+\mathrm{SiO}_{2}$. The residue was mainly silica, with a small part of the zinc, about half of the silica being soluble in sodium carbonate solntion. Here again no definite fractionation of the mineral could be observed.

Finally the action of dry hydrogen sulphide upon calamine was investigated. The mineral was heated to redness in a current of the gas and gained perceptibly in weight. The percentage data, reckoned on the original calamine, were as follows, in two experiments:

\begin{tabular}{|c|c|c|}
\hline & I. & II. \\
\hline Gain in weight $\ldots$ & 6.00 & 6.43 \\
\hline $\mathrm{SiO}_{2}$ soluble in $\mathrm{Na}_{4} \mathrm{CO}_{3} \ldots \ldots$ & 16.45 . & 20.95 \\
\hline Sulphur in residue & 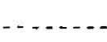 & 24.12 \\
\hline
\end{tabular}

Complete conversion of calamine into $2 \mathrm{ZnS}+\mathrm{SiO}_{2}$ implies a gain in weight of $5.80 \mathrm{per}$ cent, and it is therefore evident from the figures of the second experiment that the limit of change was approached very nearly. The 24.12 of sulphur taken up is quite close to the 26.53 per cent which is required by theory. About eight-ninths of the calamine had undergone transformation. Again no definite fractionation was detected.

The hydrogen sulphide reaction was examined still further with reference to the temperature at which it becomes effective. Even in the cold calamine is slightly attacked by the gas, but its action is unimportant until the temperature of $400^{\circ}$ is approximated. Then it becomes vigorous and the reaction goes on rapidly. A few experiments with willemite showed that it also was attacked by hydrogen sulphide, but less vigorously than calamine.

\section{PYROPHYLLITE.}

The empirical formula for pyrophyllite, $\mathrm{AlHSi}_{2} \mathrm{O}_{6}$, is apparently that of an acid metasilicate, and the mineral is therefore peculiarly available for fractional analysis. The compact variety from Deep 9506-No. 207-02_- 4 
River, N. C., was taken for examination, and a uniform sample was prepared. Analysis gave the following results:

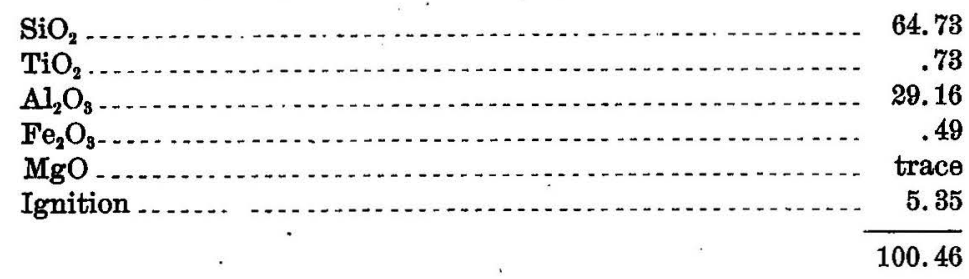

If, now, pyrophyllite is an acid metasilicate it should break up on ignition in accordance with the equation

$$
2 \mathrm{AlHSi}_{2} \mathrm{O}_{6}=\mathrm{Al}_{2} \mathrm{Si}_{3} \mathrm{O}_{9}+\mathrm{SiO}_{2}+\mathrm{H}_{2} \mathrm{O} \text {. }
$$

That is, one-fourth of the silica, or 16.18 per cent; should be liberated. The mineral itself is very slightly attacked by boiling with the sodium carbonate solution, and in an experiment of this kind only 0.72 per cent of silica was dissolved. Upon ignition under varying circumstances the following data were obtained:

Ignited ten minutes over a Bunsen burner, and then extracted with sodium carbonate solution, 1.51 per cent of $\mathrm{SiO}_{2}$ dissolved.

Ignited fifteen minutes over a Bunsen burner, 1.89 per cent became soluble.

Ignited ten minutes over a Bunsen burner and then fifteen minutes over the blast, 2.84 per cent of silica was liberated.

These results are of a different order from those given by pectolite and talc, and raise the question whether pyrophyllite, despite its ratios, is a metasilicate at all. So far as the evidence goes, it may with propriety be regarded as a basic salt of the acid $\mathrm{H}_{2} \mathrm{Si}_{2} \mathrm{O}_{5}$, and its formula then becomes

$$
\mathrm{Si}_{2} \mathrm{O}_{5}=\mathrm{Al}-\mathrm{OH} \text {. }
$$

This formula is at least as probable as the metasilicate expression, which latter rests upon assumption alone. Still other formulæ, but of greater complexity, are possible; but until we know more of the genesis and chemical relationships of pyrophyllite, speculation concerning them would be unprofitable.

By heating with ammonium chloride in an open crucible pyrophyllite is very slightly attacked. In two experiments it lost in weight 6.17 and 6.30 per cent, respectively. The excess of loss over water is due, as we have proved, to the volatilization of a little ferric and aluminic chloride. The residue of the mineral after this treatment contained no chlorine, so that no chlorhydrin-like body had been formed. The formation of such a compound, the replacement of hydroxyl by chlorine, would, if it could be effected, be a valuable datum toward determining the actual constitution of the species. The sealed tube expériments were not attempted. 


\section{SERPENTINE.}

In 1891 Clarke and Schneider published an investigation ${ }^{a}$ relative to the action of gaseous hydrochloric acid upon various minerals. Among these were the three species, serpentine, leuchtenbergite, and phlogopite, and the remainders of the original samples were fortunately at our disposal. The analyses made by Schneider are therefore directly comparable with the new data secured by us.

The serpentine, from Newburyport, Mass., was but moderately attacked upon heating with ammonium chloride. Upon leaching the contents of the sealed tube with water, 0.18 per cent of silica and 5.23 of magnesia went into solution. The washed residue and the serpentine had the following composition:

\begin{tabular}{|c|c|c|}
\hline & $\begin{array}{c}\text { Serpentine } \\
\text { (Schneider). }\end{array}$ & $\begin{array}{c}\text { Residue } \\
\text { (Steiger). }\end{array}$ \\
\hline $\mathrm{SiO}_{2}$ & 41.47 & 45.42 \\
\hline $\mathrm{Fe}_{2} \mathrm{O}_{3}, \mathrm{Al}_{2} \mathrm{O}_{3}$ & 1.73 & .88 \\
\hline MgO & 41.70 & 39.54 \\
\hline FeO & .09 & -....- \\
\hline $\mathrm{NH}_{3}$ & . & .09 \\
\hline \multirow{2}{*}{$\mathrm{H}_{2} \mathrm{O}$} & 15.06 & 14.01 \\
\hline & 100.05 & 99.94 \\
\hline
\end{tabular}

The leached residue contained 1.06 per cent of soluble silica. The amount of change effected in the mineral was evidently small, and no ammonium compound was produced.

In Schneider and Clarke's ${ }^{b}$ paper upon the ammonium chloride reaction a serpentine from the river Poldnewaja, district of Syssert, in the Urals, was studied. By a single treatment in an open crucible 4.93 per cent of magnesia became soluble in water as chloride. In a second experiment the mineral, after heating with 10 grams of ammonium chloride until volatilization ceased, was reheated with 10 grams more. Upon leaching, 14.30 per cent of magnesia went into solution. In a third trial the serpentine was thrice treated and only 10.63 per. cent of magnesia was converted into chloride. In the last case the residue was boiled with sodium carbonate solution, which extracted 3.82 per cent of silica. The same serpentine was completely decomposable by aqueous hydrochloric acid, but only moderately attacked by the dry gas. The evident irregularity of these results is yet unexplained.

\section{PHLOGOPITE.}

From Burgess, Canada. The contents of the sealed tube, after heating, showed little appearance of change. The leach water contained magnesia. Analyses as follows:

a Bull. D. S. Geol. Survey No. 78, p. 11, 1891. b Bull. U. S. Geol. Survey No. 113, p. 34, 1893. 


\begin{tabular}{|c|c|c|}
\hline & $\begin{array}{l}\text { Phlogopite } \\
\text { (Schneider). }\end{array}$ & $\begin{array}{l}\text { Residne } \\
\text { (Steiger). }\end{array}$ \\
\hline $\mathrm{SiO}_{2} \ldots$ & 39.66 & 45.03 \\
\hline $\mathrm{TiO}_{2} \ldots \ldots \ldots \ldots$ & .56 & \\
\hline $\mathrm{Al}_{2} \mathrm{O}_{3} \ldots \ldots$ & 17.00 & \\
\hline $\mathrm{Fe}_{2} \mathrm{O}_{3} \ldots$ & .27 & 15.07 \\
\hline $\mathrm{FeO}$ & .20 & \\
\hline $\mathrm{BaO}$ & .62 & $\ldots$ \\
\hline $\mathrm{MgO}$ & 26.49 & 24.94 \\
\hline $\mathrm{Na}_{2} \mathrm{O}$ & .60 & .94 \\
\hline $\mathrm{K}_{2} \mathrm{O}$ & 9.97 & 8.69 \\
\hline $\mathrm{NH}_{3}$ & :.............. & .21 \\
\hline $\mathrm{H}_{2} \mathrm{O}$ & 2.99 & 5.01 \\
\hline \multirow{2}{*}{ 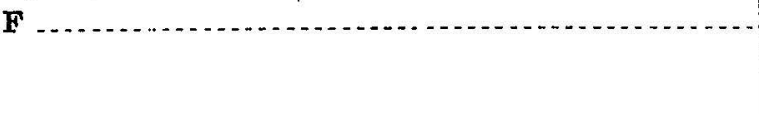 } & 2.24 & \\
\hline & 100.60 & 99.89 \\
\hline \multirow[t]{2}{*}{ Less $O$} & .94 & \\
\hline & 99.66 & \\
\hline
\end{tabular}

The residue, on boiling with sodium carbonate, gave 0.40 per cent of soluble silica. From these data it appears that phlogopite is somewhat attacked by ammonium chloride, but not strongly. No definite ammonium derivative is formed.

\section{LEUCHTENBERGITE.}

From the standard locality near Slatoust, in the Urals. When the contents of the sealed tube were leached with water, there passed into solution 0.19 per cent of alumina, plus iron, 2.10 of magnesia, and 2.03 of lime. The residue was not completely analyzed, but the few determinations made contrast with Schneider's results as follows:

\begin{tabular}{|c|c|c|}
\hline & $\begin{array}{c}\text { Leuchtenberg- } \\
\text { ite. }\end{array}$ & $\begin{array}{l}\text { Restdue } \\
\text { (Steiger). }\end{array}$ \\
\hline $\mathrm{SiO}_{2}$ & 32.27 & 32.82 \\
\hline $\mathrm{Al}_{2} \mathrm{O}_{3}$ & 16.05 & -.. \\
\hline $\mathrm{Fe}_{2} \mathrm{O}_{3} \ldots \ldots$ & 4.26 & \\
\hline $\mathrm{FeO}$ & .28 & $\ldots$ \\
\hline MgO & 29.75 & (n) \\
\hline $\mathrm{CaO}$ & -6.21 & 4.67 \\
\hline $\mathrm{NH}_{\mathbf{3}}$ & (................. & .25 \\
\hline \multirow[t]{2}{*}{$\mathrm{H}_{2} \mathrm{O}$} & 11.47 & 12.11 \\
\hline & 100.29 & - _. \\
\hline
\end{tabular}


No definite ammonium compound was formed, and the amount of decomposition was small. As the lime shown by the analysis is at least partly due to the presence of garnet as an impurity in the mineral, it will be interesting to determine the effect producible by ammonium chloride upon that species.

In Schneider and Clarke's investigation, conducted in open crucibles, this same leuchtenbergite, after three heatings with ammonium chloride, gave up 3.98 per cent of magnesia upon leaching with water. The residue contained a little magnesium oxychloride. With clinochlore from Slatoust similar results were obtained. A double heating with ammonium chloride extracted 2.12 per cent of magnesia, and a triple heating took out 3.80 per cent.

\section{XANTHOPHYLLITE.}

Variety waluewite, from the Nikolai-Maximilian mine, district of Slatoust, Urals. Examined by Schneider and Clarke, who found the mineral to be practically unattacked by gaseous hydrochloric acid, but completely decomposable by the aqueous acid. A triple treating with ammonium chloride in an open crucible took out 0.48 per cent of lime and 0.61 of magnesia. This amount of decomposition is insignificant.

\section{THE ACTION OF AMMONIUM CHLORIDE ON ROCKS.}

From the evidence so far presented it is clear that the ammoniumchloride reaction has much theoretical interest and that it adds a good deal to our knowledge of chemical constitution. But does it go any further than this and render any assistance in the elucidation of other problems? Consider, for instance, the rational analysis of silicate rocks - that is, the quantitative determination of certain mineral constituents as distinguished from the ordinary estimation of the oxides-is the reaction of any service here? We have found that among the rock-forming minerals analcite and leucite are completely transformable into ammonium salts, while elæolite and the feldspars are but little affected; olivine and the ferro-magnesian silicates also react but slightly. It would seem, therefore, as if analcite and leucite might be approximately determined by means of the reaction, the amount of change produced in a rock mixture being some measure of their quantity. To test this supposition, we have made a number of experiments, using for the purpose well-known rocks which had been studied both mineralogically and chemically.

Our method of procedure has been extremely simple, and no refinements of process have as yet been attempted. Each rock, in fine powder, was mixed with four times its weight of ammonium chloride and heated for several hours in a sealed tube to $350^{\circ}$. After cooling, the mixture was leached with water, and the amount of alkali passing into solution was estimated. From this soluble alkali the amount of analcite or leucite in the rock may be be roughly inferred, but of 
course not with any great degree of accuracy. Still an approximate estimation is better than no measurement at all and is of service to the petrographer. Fortunately the errors of the process are to some extent compensatory; a little analcite or leucite will always escape transformation, while on the other hand a little alkali will always be yielded by other species. One error renders the estimation of the alkali too low, the other makes it high, but the two tend to balance each other. In the ordinary process for separating soluble from insoluble silicates by means of aqueous hydrochloric or very dilute nitric acid the same errors occur, but with additional complications due to the solution of magnesian minerals like olivine. Furthermore, aqueous acids will not discriminate between analcite and nepheline, two species which behave very differently toward dissociating ammonium chloride. So much premised, we may pass on to the description of our experiments.

First, we examined three rocks from the Iuencite Hills, Wyoming, which were analyzed by Hillebrand and described by Cross. ${ }^{a}$ Their mineralogical composition is as follows:

A. Orendite. Contains predominating leucite and sanidine, with phlogopite, a little biotite, diopside, and amphibole, and accessory apatite and rutile.

B. Wyomingite. Contains phlogopite, leucite, diopside, and apatite.

C. Madupite. Contains predominating diopside and phlogopite, with perofskite and magnetite, in a glassy base, which has approximately the composition of leucite.

On $A$ and $B$ duplicate determinations were made, but only one in the case of $C$. The substances extracted by leaching, after treatment with ammonium chloride, are given below:

\begin{tabular}{|c|c|c|c|c|c|}
\hline & A 1. & A 2. & B 1. & B 2. & C. \\
\hline $\mathrm{Al}_{2} \mathrm{O}_{3}, \mathrm{Fe}_{2} \mathrm{O}_{3}$ & 0.26 & 0.21 & 0.64 & 0.84 & 0.21 \\
\hline $\mathrm{CaO} \ldots$ & 1.28 & 1.48 & 1.67 & 1.70 & 5.06 \\
\hline $\mathrm{K}_{2} \mathrm{O} \ldots$ & 4.68 & 4.53 & 9.50 & 0.38 & 6.81 \\
\hline $\mathrm{Na}_{2} \mathrm{O}$ & .25 & .43 & 1.33 & 1.35 & 1.08 \\
\hline
\end{tabular}

The duplicates are fairly concordant. If now we regard the $\mathrm{K}_{2} \mathrm{O}$ thus extracted as a measure of the leucite in each rock, giving the mineral its normal composition $\mathrm{KAlSi}_{2} \mathrm{O}_{6}$, we have the following percentages of the latter:

In orendite:

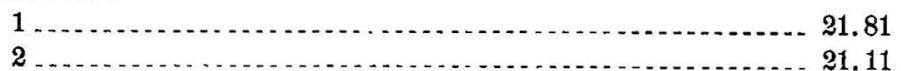

In wyomingite:

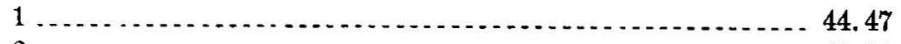

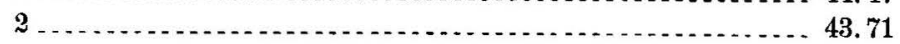

In madupite. $\ldots \ldots \ldots \ldots$

"Am. Jour. Sci., 4th series, Vol. IV, p. 115. See also Bull. U. S. Geol. Survey No. 168, pp. 85 and 80 , 1900 , for analyses. 
Two other leucite rocks were also studied by us, as follows, both being given in duplicate :

D. Missourite. Highwood Mountains, Montana. Described by Weed and Pirsson. $a$ Analyzed by E. B. Hurlbut. Contains augite and leucite, with apatite, iron oxides, olivine, and biotite. Some zeolites and analcite are also present.

E. Leucitite, Bearpaw Mountains, Montana. Described by Weed and Pirsson. $b$ Analyzed by H. N. Stokes. An olivine-free leucite basalt. Contains lencite, augite, iron oxides, rarely biotite, and a very small amount of glassy base.

The following substances were taken out by the ammonium chloride reaction:

\begin{tabular}{|c|c|c|c|c|}
\hline . & D 1. & D 2. & E 1. & E 2. \\
\hline $\mathrm{CaO}$ & 1.73 & 1.70 & 0.89 & 1.29 \\
\hline $\mathrm{K}_{2} \mathrm{O} \ldots$ & 4.09 & 3.74 & 6.19 & 6.16 \\
\hline $\mathrm{Na}_{2} \mathrm{O} \ldots \ldots \ldots$ & .59 & .64 & 1.44 & 1.47 \\
\hline
\end{tabular}

Hence we have for leucite-

In missourite 19.06 and 17.43

In lencitite 28.84 and 28.70

It will be observed that the extracted soda is neglected in the computation. In missourite it may represent analcite; in the other rocks it perhaps belongs to a sodium equivalent of leucite, or it may come from some still different source. At all events, it serves to indicate some of the uncertainties attending the application of the method.

Among the rocks containing analcite as an essential constituent, only two were available for our purposes. They are:

F. Analcite-basalt, from Basin, Colorado. Described by Cross. $c$ Analyzed by Hillebrand. Contains phenocrysts of augite, olivine, and analcite; also magnetite, and minor amounts of alkali feldspars, biotite, and apatite.

G. Heronite, from Heron Bay, Lake Superior. Described by Coleman. ${ }^{d}$ Contains analcite, orthoclase, labradorite, ægirite, limonite, and calcite.

By treatment with ammonium chloride the following bases were extracted from these rocks, determinations being made in duplicate :

\begin{tabular}{|c|c|c|c|c|}
\hline & F 1. & $\mathrm{~F} 2$. & G 1. & G 2. \\
\hline $\mathrm{CaO} \ldots \ldots . . . . . .$. & 1.74 & 2.28 & 1.64 & 1.62 \\
\hline $\mathrm{K}_{2} \mathrm{O}$ & .46 & .49 & .21 & .18 \\
\hline $\mathrm{Na}_{2} \mathrm{O}$ & 3.42 & 3.29 & 6.04 & 6.37 \\
\hline
\end{tabular}

a Am. Jour. Sci., 4th series, Vol. II, p. 315; Bull. U. S. Geol. Survey No. 168, p. 133. $b$ Am. Jour. Sci., 4th series, Vol. II, p. 143; Bull. U. S. Geol. Survey No. 168, p. 136. cSee Bull. U. S. Geol. Surrey No. 168, p. 146. ¿Jour. Geology, Vol. VII, p. 431. 
Hence, reckoning the soda as equivalent to normal analcite, $\mathrm{NaAlSi} \mathrm{O}_{6} \cdot \mathrm{H}_{2} \mathrm{O}$, we have as percentages of the latter:

In analcite-basalt

26. 33 and 25.33

In heronite

46.51 and 49.05

According to Coleman's computations, heronite contains 47 per cent of analcite. This figure agrees quite perfectly with our experimental determination.

In order to gain some notion of the extent to which other rocks, containing neither analcite nor leucite, might be affected by the reaction with ammonium chloride, four examples were chosen from among the many which have been studied in this laboratory. ${ }^{a}$ They were:

H. Phonolite, Uvalde County, Tex. Contains sanidine, nepheline, and ægirite, with very little brown hornblende, augite, and magnetite.

I. Soda-granite-porphyry, Merced River, Mariposa County, Cal. Contains feldspar, largely albite, hornblende, muscovite, epidote, apatite, anā iron ore.

J. Granitite, Placerville Canal, Eldorado County, Cal. Contains biotite, orthoclase, plagioclase, and quartz.

K. Augite-latite, Table Mountain, Tuolumne County, Cal. Contains labradorite, olivine, augite, and magnetite.

The bases extracted from these four rocks were as follows, in percentages:

\begin{tabular}{|c|c|c|c|c|}
\hline & H. & I. & J. & $\mathbf{K}$. \\
\hline $\mathrm{Al}_{2} \mathrm{O}_{3}, \mathrm{Fe}_{2} \mathrm{O}_{3} \ldots \ldots$ & 0.33 & 0.19 & 0.58 & ......... \\
\hline $\mathrm{CaO} \ldots \ldots \ldots \ldots$ & .22 & .29 & none & 0.66 \\
\hline $\mathrm{K}_{2} \mathrm{O}$ & .41 & .20 & .20 & 1.21 \\
\hline $\mathrm{Na}_{2} \mathrm{O} \ldots \ldots$ & 4.38 & .33 & .23 & .66 \\
\hline
\end{tabular}

Among these rocks only the first one, the phonolite, was seriously affected; and it is difficult to account for the large amount of soda extracted. Neither nepheline nor ægirite taken alone gives up nearly so much soda as was liberated in this case, and no other sodium mineral has been reported present in the rock. In the other cases the amount of extraction is small and amounts to no more than the plus error, which was pointed out at the beginning of this discussion.

Taking all things into account, it seems probable that the analytical method proposed, although far from exact, is capable of some development, and is likely to yield results of some value. Perhaps it might be improved by taking into account the quantities of ammonia retained by the washed residues. From that source one estimate could be derived, and from the alkali in solution another; the two should give better information than either determination alone. But the precision of ordinary analytical processes is not to be expected here, and only useful approximations can be anticipated. 
SUMMARY.

In the foregoing pages we have considered the action of ammonium chloride, at its temperature of dissociation, upon 31 mineral species. We have shown that its influence upon various silicates differs very widely, but that in general it is a much more powerful reagent than has been generally supposed. The results, in brief, are as follows:

First. Analcite, leucite, natrolite, and scolecite, heated with dry ammonium chloride to $350^{\circ}$ in a sealed tube, yield alkaline chlorides and an ammonium aluminum silicate, which is stable at $300^{\circ}$. The reaction is simply one of double decomposition, the sodium or potassium of the original silicate being completely replaced by ammonium. Analcite and leucite give the same product, $\mathrm{NH}_{4} \mathrm{AlSi}_{2} \mathrm{O}_{6}$. Natrolite and scolecite yield the salt $\left(\mathrm{NH}_{4}\right)_{2} \mathrm{Al}_{2} \mathrm{Si}_{3} \mathrm{O}_{10}$. The latter compound is a derivative of orthotrisilicic acid, $\mathrm{H}_{8} \mathrm{Si}_{3} \mathrm{O}_{10}$; and in a separate section of the memoir its constitution and its relations to other trisilicic acids are considered.

Second: A similar reaction, a double decomposition, takes place incompletely with stilbite, heulandite, chabazite, thomsonite, laumontite, and pollucite. Part of the monoxide base is removed and replaced by ammonium, without change of atomic ratios. Cancrinite is also vigorously attacked, and partially transformed into a zeolitic body.

Third. Pectolite, wollastonite, apophyllite, datolite, ilvaite, and calamine are violently acted upon by ammonium chloride, and their molecules seem to be almost completely broken down. The products of the reactions are mixtures, and no ammonium silicates are formed.

Fourth. Elæolite, sodalite, riebeckite, olivine, serpentine, phlogopite, prehnite, orthoclase, albite, oligoclase, ægirite, pyrophyllite, leuchtenbergite, and xanthophyllite are but slightly attacked by dissociating ammonium chloride.

In the closing section of the work we have shown that the ammonium chloride reaction may be applied to an approximate quantitative determination of analcite and leucite in rocks, thereby aiding" somewhat in the estimation of their mineralogical composition. 



\title{
PUBLICATIONS OF UNITED STATES GEOLOGICAL SURVEY.
}

\author{
[Bulletin No. 207.]
}

The serial publications of the United States Geological Survey consist of (1) Annual Reports, (2) Monographs, (3) Professional Papers, (4) Bulletins, (5) Mineral Resources, (6) Water-Supply and Irrigation Papers, (7) Topographic Atlas of United Statesfolios and separate sheets thereof, (8) Geologic Atlas of United States-folios thereof. The classes numbered 2, 7, and 8 are sold at cost of publication; the others are distributed free. A circular giving complete lists may be had on application.

The Bulletins, Professional Papers; and Water-Supply Papers treat of a variety of subjects, and the total number issued is large. They have therefore been classified into the following series: A, Economic geology; B, Descriptive geology; C, Systematic geology and paleontology; D, Petrography and mineralogy; E, Chemistry and physics; F, Geography; G, Miscellaneous; H, Forestry; I, Irrigation; J, Water storage; K, Pumping water; L, Quality of water; M, Methods of hydrographic investigation; N, Water power; O, Underground waters; P, Hydrographic progress reports. This bulletin is the thirty-sixth in Series $E$, the complete list of which follows (all are bulletins thus far):

\section{SERIES E, CHEMISTRY AND PHYSICS.}

9. Report of work done in the Washington laboratory during the fiseal year 1883-84, by F. W. Clarke and T. M. Chatart. $1884.40 \mathrm{pp}$.

14. Electrical and magnetic properties of the iron carburets, by Carl Barus and Vineent Strouhal. 1885. $238 \mathrm{pp}$.

27. Report of work done in the Division of Chemistry and Physics, mainly during the year 1884-85. 1886. $80 \mathrm{pp}$.

32. Lists and analyses of the mineral springs of the United States (a preliminary study), by Albert

C. Peale. 1886. 235 pp.

35. Physical properties of the iron carburets, by Carl Barus and Vincent Strouhal. 1886. 62 pp.

36. Subsidence of fine solid particles in liquids, by Carl Barus. $1886.58 \mathrm{pp}$.

42. Report of work done in the Division of Chemistry and Physies, mainly during the fiseal year 1885-86, by F. W. Clarke. 1887. 152 pp., 1 pl.

47. Analyses of waters of the Yellowstone National Park, with an account of the methods of analyses employed, by Frank Austin Gocch and James Edward Whitfield. $1888.84 \mathrm{pp}$.

52. Subaerial decry of rocks and origin of the red color of certain formations, by Israel Cook Russell. 1889.65 pp., 5 pls.

54. On the thermoelectrie measurement of high temperatures, by Carl Barus. 1889.313 pp., 11 pls.

55. Report of work done in the Division of Chemistry and Physics, mainly during the fiscal year 1886-87, by Frank Wigglesworth Clarke. 1889. $96 \mathrm{pp.}$

60. Report of work done in the Division of Chemistry and Physics, mainly during the fiscal year 1887-88. 1890 . $174 \mathrm{pp}$.

64. Report of work done in the Division of Chemistry and Physies, mainly during the fiscal year $1888-89$, by F. W. Clarke. 1890.60 pp.

68. Earthquakes in California in 1889, by James Edward Keeler. 1890.25 pp.

73. The viscosity of solids, by Carl Barus. 1891. xii, 139 pp., 6 pls.

78. Report of work done in the Division of Chemistry and Physies, mainly during the fiseal year 1889-90, by F. W. Clarke. 1891. 131 pp.

90. Report of work done in the Division of Chemistry and Physies, mainly during the fiscal year 1890-91, by F. W. Clarke. 1892.77 pp.

92. The compressibility of liquids, by Carl Barus. $1892.96 \mathrm{pp} ., 29 \mathrm{pls}$.

94. The mechanism of solid viseosity, by Carl Barus. $1892.138 \mathrm{pp.}$

95. Earthquakes in California in 1890 and 1891, by Edward Singleton Holden. $1892.31 \mathrm{pp}$.

96. The volume thermodynamics of liquids, by Carl Barus. $1892.100 \mathrm{pp}$. 


\section{PUBLICATIONS OF UNITED STATES GEOLOGICAL SURVEY.}

103. High temperature work in igneous fusion and ebullition, chiefly in relation to pressure, by Carl Barus. 1893 . $57 \mathrm{pp} ., 9$ pls.

112. Earthquakes in California in 1892, by Charles D. Perrine. $1893.57 \mathrm{pp}$.

113. Report of work done in the Division of Chemistry and Physies during the fiscal years 1891-92 and $1892-93$, by F. W. Clarke. $1893.115 \mathrm{pp}$.

114. Earthquakes in Galifornia in 1893, by Charles D. Perrine. 1894. 23 pp.

125. The constitution of the silicates, by Frank Wigglesworth Clarke. $1895.100 \mathrm{pp}$.

129. Earthquakes in California in 1894, by Charles D. Perrine. 1895, $25 \mathrm{pp.}$

147. Earthquakes in California in 1895, by Charles D. Perrine. $1896.23 \mathrm{pp}$.

148. Analyses of rocks, with a chapter on analytical methods, laboratory of the United States Geological Survey, 1880 to 1896, by F. W. Clarke and W. F. Hillebrand. $1897.306 \mathrm{pp}$.

155. Earthquakes in California in 1896 and 1897, by Charles D. Perrine. $1898.47 \mathrm{pp}$.

161. Earthquakes in California in 1898 , by Charles D. Perrine. $1899.31 \mathrm{pp} ., 1 \mathrm{pl}$.

167. Contributions to chemistry and mineralogy from the laboratory of the United States Geological Survey; Frank W. Clarke, Chief Chemist. 1900 . $166 \mathrm{pp}$.

168. Analyses of rocks, laboratory of the United States Geological Survey, 1880 to 1899 , tabulated by F. W. Clarke. 1900 . $308 \mathrm{pp}$.

176. Some principles and methods of rock analysis, by W. F. Hillebrand. $1900.114 \mathrm{pp}$.

186. On pyrite and marcasite, by H. N. Stokes. $1900.50 \mathrm{pp}$.

207. The action of ammonium chloride upon silicates, by F. W. Clarke and George Steiger. 1902. $67 \mathrm{pp}$.

Correspondence should be audressed to-

The Director,

United States Geological Survey,

November, 1902 .

WASHington, D. C. 


\section{LIBRARY CATALOGUE SLIPS.}

[Take this leaf out and paste the separated titles upon three of your calalogue cards. The first and second titles need no addition; over the third write that subject under which you would place the book in your library.]

United States. Department of the interior. (U.S. Gieological survey.) Bulletin No. 207 Series E, Chemistry and physics, 36 | Department of the interior | United States geological survey | Charles D. क्ष $\quad$ Walcott, director $|-|$ The $\mid$ action of ammonium chloride $\mid$ upon silicates | by | FrankWigglesworthClarke | and | George Steiger | [Vignette] |

Washington | government printing office | 1902

$8^{\circ}$. $57 \mathrm{pp}$.

Clarke (Frank Wigglesworth) and Steiger (George).

Bulletin No. 207 Series E, Chemistry and physics, 36 | Department of the interior | United States geological survey | Charles D. Walcott, director $|-|$ The $\mid$ action of ammonium chloride $\mid$ upon silicates | by | FrankWigglesworth Clarke | and | George Steiger | [Vignette] |

Washington | government printing office | 1902

$8^{\circ} .57 \mathrm{pp}$.

Bulletin No. 207 Series E, Chemistry and physics, 36 | Department of the interior | United States geological survey | Charles D. Walcott, director $|-|$ The $\mid$ action of ammonium chloride | upon silicates | by | FrankWigglesworth Clarke | and | GeorgeSteiger | [Vignette] |

Washington | government printing office | 1902

$8^{\circ}$. $57 \mathrm{pp}$. 






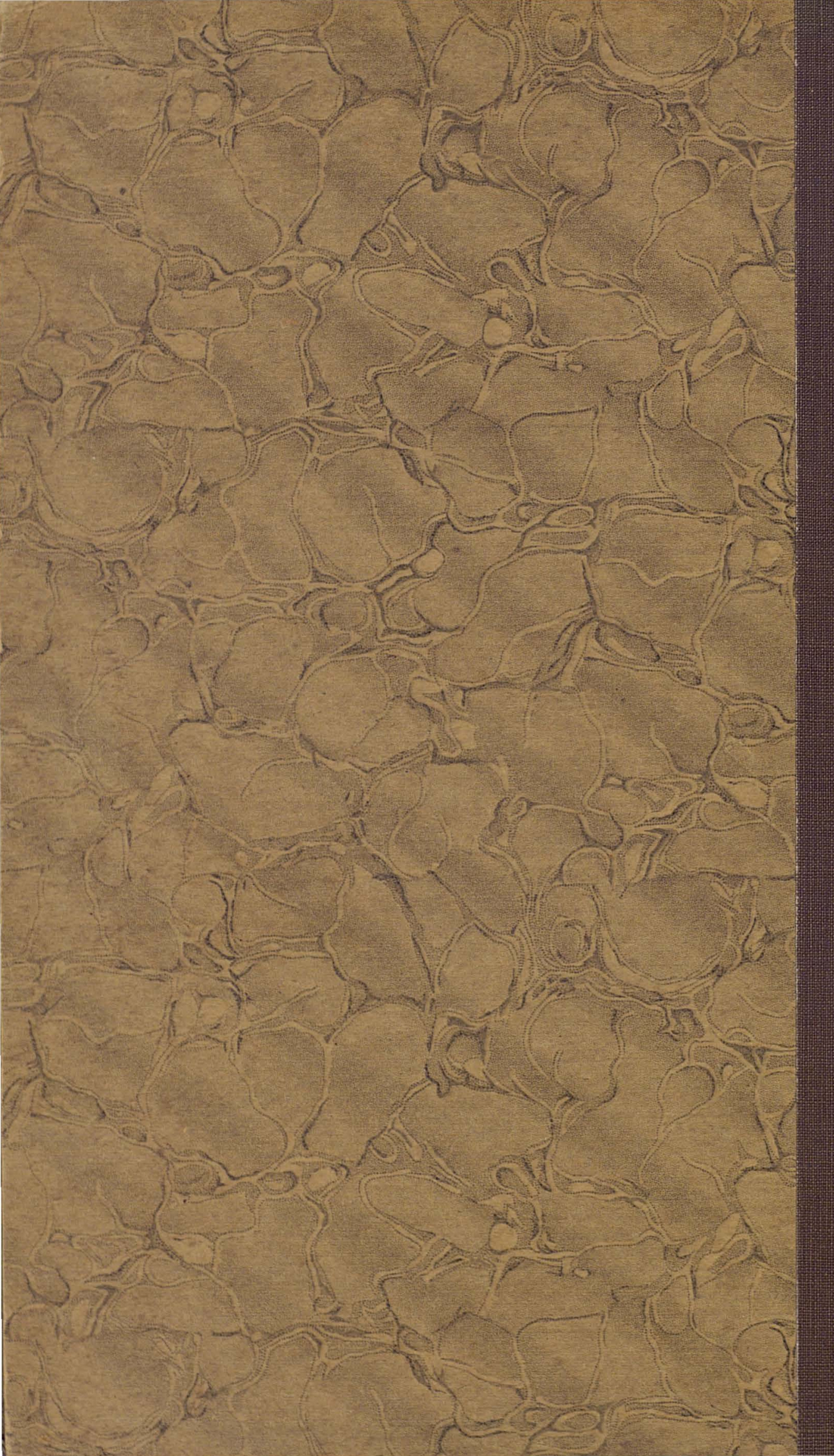

